\title{
Constraining mass-diameter relations from hydrometeor images and cloud radar reflectivities in tropical continental and oceanic convective anvils
}

\author{
E. Fontaine ${ }^{1}$, A. Schwarzenboeck ${ }^{1}$, J. Delanoë ${ }^{2}$, W. Wobrock ${ }^{1}$, D. Leroy ${ }^{1}$, R. Dupuy ${ }^{1}$, C. Gourbeyre ${ }^{1}$, and A. Protat ${ }^{2, *}$ \\ ${ }^{1}$ Université Blaise Pascal, Laboratoire de Météorologie Physique, Aubière, France \\ ${ }^{2}$ Laboratoire Atmosphère, Milieux et Observations Spatiales, UVSQ, Guyancourt, France \\ * now at: Center for Australian Weather and Climate Research, Melbourne, Australia
}

Correspondence to: E. Fontaine (e.fontaine@opgc.univ-bpclermont.fr)

Received: 9 January 2014 - Published in Atmos. Chem. Phys. Discuss.: 28 January 2014

Revised: 13 September 2014 - Accepted: 15 September 2014 - Published: 29 October 2014

\begin{abstract}
In this study the density of ice hydrometeors in tropical clouds is derived from a combined analysis of particle images from 2-D-array probes and associated reflectivities measured with a Doppler cloud radar on the same research aircraft. Usually, the mass-diameter $m(D)$ relationship is formulated as a power law with two unknown coefficients (pre-factor, exponent) that need to be constrained from complementary information on hydrometeors, where absolute ice density measurement methods do not apply. Here, at first an extended theoretical study of numerous hydrometeor shapes simulated in 3-D and arbitrarily projected on a 2-D plan allowed to constrain the exponent $\beta$ of the $m(D)$ relationship from the exponent $\sigma$ of the surface-diameter $S(D)$ relationship, which is likewise written as a power law. Since $S(D)$ always can be determined for real data from 2-D optical array probes or other particle imagers, the evolution of the $m(D)$ exponent can be calculated. After that, the pre-factor $\alpha$ of $m(D)$ is constrained from theoretical simulations of the radar reflectivities matching the measured reflectivities along the aircraft trajectory.

The study was performed as part of the Megha-Tropiques satellite project, where two types of mesoscale convective systems (MCS) were investigated: (i) above the African continent and (ii) above the Indian Ocean. For the two data sets, two parameterizations are derived to calculate the vertical variability of $m(D)$ coefficients $\alpha$ and $\beta$ as a function of the temperature. Originally calculated (with T-matrix) and also subsequently parameterized $m(D)$ relationships from this study are compared to other methods (from literature) of calculating $m(D)$ in tropical convection. The significant
\end{abstract}

benefit of using variable $m(D)$ relations instead of a single $m(D)$ relationship is demonstrated from the impact of all these $m(D)$ relations on $Z$-CWC (Condensed Water Content) and $Z$-CWC- $T$-fitted parameterizations.

\section{Introduction}

The French-Indian satellite Megha-Tropiques (MT), launched in 2011, is primarily devoted to improve our knowledge about the life cycle of tropical convective systems over ocean and continents, the environmental conditions for their formation and evolution, their water budget, and the associated water vapor transport. The most relevant instrument on the MT satellite for cloud studies is the MADRAS microwave imager having nine frequencies $(18.7 \mathrm{GHz}$ to $157 \mathrm{GHz})$. Similar satellite missions for tropical cloud studies were TRMM (Tropical Rainfall Measurement Mission, Huffman et al., 2007; Jensen and Del Genio, 2003) or SSM/I (Special Sensor Microwave/Imager, Spencer et al., 1989). To retrieve the surface rain rate from the brightness temperatures measured by above satellite missions, retrieval algorithms, as for example BRAIN (Viltard et al. 2006), are used, which have major sources of uncertainty due to the variability of the density of ice crystals in the tropical atmosphere.

With the overall objective to learn more about the variability of microphysical properties (in particular density) of ice crystals in tropical convective clouds, two aircraft campaigns 
(detailed in Sect. 2) were conducted within the frame of the MT project.

The main focus of this study is to characterize the statistical relationship between the mass and the length (hereafter $m(D))$ of ice crystals by developing a retrieval technique that combines radar reflectivity and particle imagery, in order to produce reliable calculations of the condensed water content (CWC) as a function of time and along flight trajectory. This study focuses on the variability of the $m(D)$ power law relationship in tropical convective clouds. Several previous studies have shown significant variability in $m(D)$ including pre-factor and exponent of the power law for different flights within one and the same aircraft campaign (McFarquhar et al., 2007; Heymsfield et al., 2010a, hereafter denoted H10). Concerning the ice crystal growth by pure vapor diffusion it is well known that the crystal habit is primarily a function of temperature and supersaturation (Bailey and Hallett 2004, 2009; Kobayashi 1993). In addition, collision growth processes (aggregation and riming) in dynamically more active clouds tremendously complicate the resulting crystal habits and associated properties (crystal geometry, density, optical properties). Therefore, and to improve our understanding of microphysical processes in clouds in general, it is necessary to get a more realistic description of ice crystals and particularly a description of their mass as a function of their size (Schmitt and Heymsfield, 2010; hereafter SH2010).

Cloud observations are often related to radar measurements or satellite observations and associated inversion algorithms. Thus, the forward modeling of the remote sensing signal (active or passive) and the retrieval of cloud microphysics is linked to the model capacity to simulate the radiative transfer through a population of ice crystals of complex habits. Numerous previous studies already related cloud radar reflectivity (usually at a frequency of 94 or $35 \mathrm{GHz}$ ) and in situ measurements of cloud microphysical properties. For instance, Protat et al. (2007) and Hogan et al. (2006) calculated the total water content assuming a constant mass-size relationship for all clouds. Derived $Z-C W C$ relationships often need to be corrected as a function of temperature. This somewhat translates the lack of knowledge of the temperature dependency of mass-size relationships.

The most usual empirical expression used to predict the mass for various types of ice crystal shapes is formulated as a power law (Locatelli and Hobbs 1974; Mitchell 1996, hereafter M96; (Heymsfield and Westbrook, 2010; McFarquhar et al., 2007) which is usually a function of the maximum length (hereafter $D_{\max }$ ) or the mean diameter (average of the maximum length in the $y$ axis and the maximum value of $x$ axis; (Brown and Francis 1995, hereafter BF95) of the 2-D hydrometeor images.

In this paper the mass $m$ (in gram) is presented as a power law relation of $D_{\max }$ (in centimeters):

$m\left(D_{\max }\right)=\alpha \cdot D_{\max }^{\beta}$
In other studies the mass (and thus density) of hydrometeors was determined following various principles. For example, ice crystals were collected on a sheet of plastic or a Petri dish. After taking microphotographs of the crystals, these were melted to deduce their mass from the resulting hemispherical drops (Locatelli and Hobbs 1974; Mitchell et al., 1990). Another method used is to classify hydrometeors according to their crystal habits associated to specific $m(D)$ relations for individual habits, following the scheme given by Magono and Lee (1966). Furthermore, when the CWC mass concentration is measured directly with simultaneously 2-D images of hydrometeors, $m(D)$ relationships are derived from integral CWC data and corresponding particle size distributions (hereafter PSD) extracted from the images. BF95 used a Lyman- $\alpha$ absorption hygrometer (Nicholls et al., 1990) and a 2-D optical array probe (OAP) simultaneously to determine coefficients $\alpha$ and $\beta$ for cirrus clouds. Heymsfield et al. (2002) developed an expression of the crystal mass as a function of $D_{\max }$ and the area ratio $A_{\mathrm{r}}$ (the projected area of an ice particle normalized by the area of a disc having the same $D_{\max }$ ) for bullet-rosettes present in cirrus clouds. This approach was confronted with real measurements of CWC measured with a counterflow virtual impactor (Ogren et al. 1985) and corresponding 2-D images (OAP 2DC and 2DP) in cirrus clouds from airborne measurements. A detailed description of the particle habits which is needed for the previous approach was provided by the high resolution 2-D images from the cloud particle imager (CPI) (Lawson et al., 1998). (Heymsfield et al., 2002 then used the retrieved $m(D)$ relationships to compute $\mathrm{Ka}$-band radar equivalent reflectivities, which are in good agreement with measured reflectivities.

Baker and Lawson (2006; hereafter B\&L) introduced a new scheme which is a combination of fundamentals geometric parameters (perimeter, width, $D_{\max }$ and projected area) of the 2-D images to deduce the mass of individual particles. This method was validated against the data set of Mitchell et al. (1990) and has the advantage of not requiring particle habit assumptions.

McFarquhar et al. (2007) derived vertical profiles of $m(D)$ relationships in the stratiform part of mesoscale convective systems (hereafter MCS) above the North American continent within and below the melting layer. $\alpha$ and $\beta$ coefficients were calculated from measured reflectivities and PSD deduced from the OAP 2DC and 2DP probes.

SH2010 have simulated the aggregation of plates or columns. Therein, fractal 2-D and 3-D analyses, calculated from the box counting method (Tang and Marangoni 2006), suggested that the fractal coefficient in the 3-D space is equal to $\beta$. This allowed deriving a relationship that calculates the exponent $\beta$ from the 2-D fractal dimension of the 2-D images. Once $\beta$ has been fixed, the pre-factor $\alpha$ is calculated from the area measurement with OAP of ice hydrometeors.

H10 have calculated $m(D)$ coefficients by minimizing the differences with measured $\mathrm{CWC}$ for different airborne 
campaigns. They demonstrate that a strong relationship exists between $\alpha$ and $\beta$ coefficients, which was mathematically demonstrated with a gamma distribution parameterizing the PSD. Furthermore, they argue that the BF95 relationship overestimates the prefactor $\alpha$ for stratiform clouds, whereas $\alpha$ is underestimated for convective clouds.

In our study, bulk CWC measurements were either not performed (MT2010) or of limited value for MT2011. A deep cone unattended version of the Nevzorov probe was installed under the fuselage, showing some enrichment due to ice crystals bouncing from the aircraft skin. In addition, a relatively high offset led to probe saturation at roughly $1 \mathrm{~g} \mathrm{~m}^{-3}$.

In order to calculate CWC, cloud ice density of hydrometeors needs to be derived from joint analysis of the radar reflectivity measured by the $94 \mathrm{GHz}$ cloud radar, RASTA (Protat et al. 2009), and cloud particle images measured simultaneously with 2-D array probes on the same aircraft. The $\alpha$ and $\beta$ coefficients are constrained from particle imagery and from theoretical simulations of ice crystal images, combined with subsequent simulations of cloud reflectivities compared to measured ones. In the following Sect. 2 the MT aircraft campaigns and corresponding in situ microphysical measurements are described. The methodology to retrieve $m(D)$ coefficients for CWC calculations from the variability of the hydrometeor images and corresponding radar reflectivity measurements is presented in Sect. 3. Section 4 then presents results on the variability (every $5 \mathrm{~s}$ during flight) of calculated $m(D)$ coefficients. Then the coefficients are parameterized (as a function of temperature, also mean value) and compared with existing $m(D)$ relations. All these $m(D)$ relations are applied to data sets of the two MT flight campaigns, thus calculating $\mathrm{CWC}$, in order to study their impact on $Z$-CWC and Z-CWC- $T$ parameterizations fitted to corresponding measured reflectivity data.

\section{Cloud data from the Megha-Tropiques flight campaigns}

Two airborne measurement campaigns were conducted with the French Falcon 20 research aircraft from SAFIRE (Service des Avions Français Instrumentés pour la Recherche en Environnement). During the first campaign, The Falcon20 was flown out from Niamey (Niger) in August 2010 (hereafter MT2010) during the monsoon season above the West African continent. The second campaign was conducted above the Indian Ocean between November and December 2011 (hereafter MT2011) at Gan (Maldives).

While African continental MCS in the monsoon seasons are due to the convergence of wet colder air masses from the ocean with dry warmer air masses, the convection over the Indian Ocean is due to the buoyancy of wet air masses leading to weaker convection in our case. Further studies (Cetrone and Houze, 2009; Frey et al., 2011) have discussed differences in the intensity of tropical convection between pure continental African MCS and more maritime MCS with some continental influence (for example South Asia for oceanic convection north of Australia). These studies conclude on deeper convective systems and strongest precipitation for African MCS as compared to oceanic convection. This means that growth processes of hydrometeors in oceanic convection were to a non-negligible extent due to vapor diffusion, which produced many dendrites and plates that were observed. In contrast, for West African MCS the hydrometeor growth is more influenced by riming and aggregation processes, thus leading to observations of abundant ice crystal aggregates and graupel-type particles.

A brief description of the research flights and sampled convective cloud systems selected for this study is presented in Table 1. Cloud systems observed during MT2010 were typically MCS, consisting of a convective and a trailing stratiform part (Houze 2004). Most of the flights were performed in the stratiform part of these MCS within the temperature range down to $-35^{\circ} \mathrm{C}$. During MT2011, two types of systems were observed: in the first part of the campaign two MCS systems were sampled, whereas in the second part the convection was much less organized and only more isolated smaller systems were encountered. In general, flights were performed in the anvil at various constant altitude levels as close as possible and parallel to the convective line for MT2010. For MT2011 flight pattern were performed downstream the convective cell, but not crossing the most active part.

The Falcon 20 was equipped with active remote sensing and cloud-microphysics in situ instrumentation. Next to the Doppler cloud radar RASTA (Protat et al., 2009) in situ measurements of microphysical properties were performed using a new generation of optical array probes (OAPs): the 2-D stereo probe (2D-S) from Stratton Park Engineering Company (SPEC) Inc. which allows to monitor 2-D images in the size range $10-1280 \mu \mathrm{m}$, and the precipitation imaging probe (PIP) from droplet measurement technologies (DMT) which measures hydrometeors in the size range of 100-6400 $\mu \mathrm{m}$.

Figure 1 presents exemplary 2-D images of ice crystals observed during the two campaigns. 2-D images are presented as a function of altitude. On the left side of Fig. 1 hydrometeors are shown that were observed in continental MCS, whereas on the right side hydrometeors observed in oceanic MCS are presented. In the two first levels $\left(-1\right.$ and $\left.-5^{\circ} \mathrm{C}\right)$ hydrometeors are similar with one exception where at $-5^{\circ} \mathrm{C}$ a dendrite shows up for MT2011. For other levels, ice crystal shapes are generally different. Besides aggregates, significant amounts of individual large pristine ice crystals such as dendrites (typically due to water vapor diffusion only) could be observed for MT2011, whereas 2-D images for MT2010 generally look more like aggregates (more or less rimed) and sometimes graupels.

In order to derive particle size distributions and aspect ratios from the 2-D images, standard corrections of the OAP data were performed. In particular, rejection of 2-D images 
Table 1. List of Falcon 20 research flights used in this study.

\begin{tabular}{lllll}
\hline Flight program & Flight number & Day & Hour (UTC) & Cloud type \\
\hline & Flight 15 & $2010 / 08 / 06$ & $16: 10-19: 00$ & MCS squall line \\
& Flight 17 & $2010 / 08 / 10$ & $08: 45-11: 60$ & MCS squall line \\
MT2010 Continental & Flight 18 & $2010 / 08 / 13$ & $13: 20-16: 25$ & MCS squall line \\
& Flight 19 & $2010 / 08 / 17$ & $10: 30-13: 40$ & MCS squall line \\
& Flight 20 & $2010 / 08 / 17$ & $23: 35-02: 40$ & MCS squall line \\
\hline \multirow{3}{*}{ MT2011 Oceanic } & Flight 45 & $2011 / 11 / 27$ & $05: 30-08: 50$ & MCS ITCZ \\
& Flight 46 & $2011 / 11 / 27$ & $15: 15-18: 25$ & MCS ITCZ \\
& Flight 49 & $2011 / 12 / 06$ & $13: 25-15: 40$ & isolated convective system \\
& Flight 50 & $2011 / 12 / 08$ & $06: 00-09: 00$ & isolated convective system \\
\hline
\end{tabular}
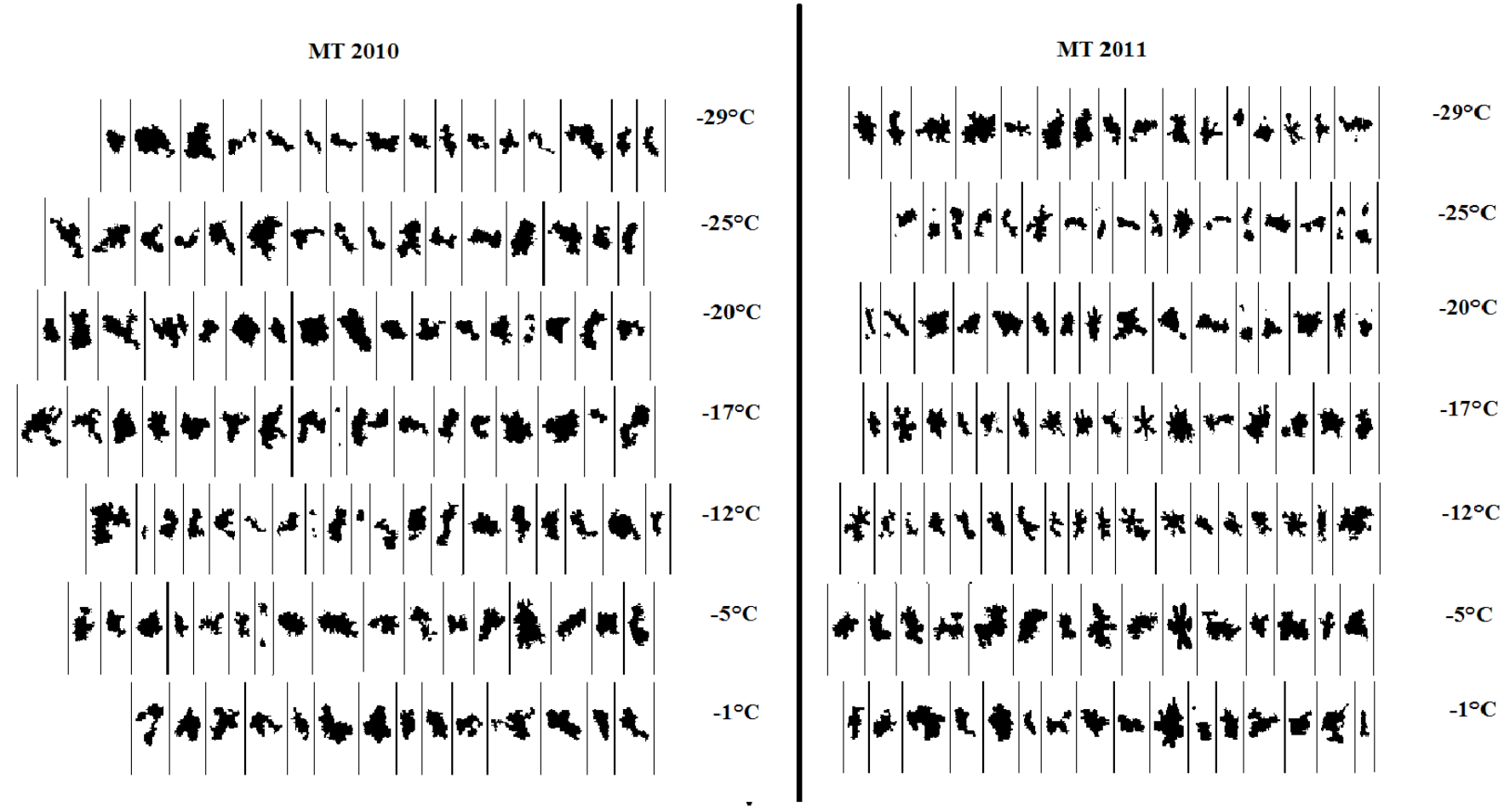

Figure 1. Examples of 2-D images recorded by the precipitation imaging probe PIP for MT2010 and MT2011. Selected hydrometeor images are presented as a function of temperature in ${ }^{\circ} \mathrm{C}$ and have sizes between $2 \mathrm{~mm}$ to $4 \mathrm{~mm}$.

due to shattering (Field et al., 2006, Korolev and Isaac, 2005, Field et al., 2003) and also rejection of splashes were applied. The inter-arrival time based shattering analysis is performed continuously to packages of 2000 particles along the flight track and 2-D image data are corrected accordingly as a function of time. Moreover, reconstruction of truncated images which are only partially recorded was applied (Heymsfield and Parrish, 1978). Finally, the pixel resolution (10 $\mu \mathrm{m}$ for the 2D-S, $100 \mu \mathrm{m}$ for the PIP) is corrected for the true air speed (Baumgardner and Korolev, 1997), in order to account for the fixed speed setting during data acquisition.

2-D images recorded with 2D-S and PIP probes were processed using the software developed at LaMP (Laboratoire de Météorologie Physique) for CPI images (Lefèvre, 2007) and improved for black and white 2-D images in order to extract a large variety of geometrical parameters, such as maximum diameter $D_{\max }$, width perpendicular to $D_{\max }$ direction, projected area (hereafter $\mathrm{Sp}$ ), and perimeter. Then for each probe, the number particle size distribution (PSD) and the mean aspect ratio distribution (hereafter AsD) are calculated as a function of $D_{\max }$. With these distributions we build composite distributions for PSD and AsD from both probes. The size range of these distributions spans from 50 to 6450 microns in $D_{\max }$. Equations (2) and (3) describe the simple interpolation scheme used to build the composite number $\mathrm{PSD}$, an analogue scheme is used to derive AsD composite 
distributions.

$$
\begin{aligned}
& \sum_{D_{\max }=50}^{D_{\max }<6450} N\left(D_{\max }\right) \cdot \Delta D_{\max }=\sum_{D_{\max }=50}^{D_{\max }<450} N_{2 \mathrm{D}-\mathrm{S}}\left(D_{\max }\right) \cdot \Delta D_{\max } \\
& +C_{1}\left(D_{\max }\right) \cdot \sum_{D_{\max }=450}^{D_{\max }<950} N_{2 \mathrm{D}-\mathrm{S}}\left(D_{\max }\right) \cdot \Delta D_{\max } \\
& +C_{2}\left(D_{\max }\right) \cdot \sum_{\max }^{D_{\max }<950} N_{\mathrm{PIP}}\left(D_{\max }\right) \cdot \Delta D_{\max } \\
& +\sum_{D_{\max }=450}^{D_{\max }<6450} N_{\mathrm{PIP}}\left(D_{\max }\right) \cdot \Delta D_{\max }
\end{aligned}
$$

with

$$
\begin{aligned}
& C_{1}\left(D_{\max }\right)+C_{2}\left(D_{\max }\right)=1 ; \\
& \text { and } C_{2}\left(D_{\max }\right)=\left(D_{\max }-450\right) /(950-450)
\end{aligned}
$$

These composite distributions are mainly composed of three parts. The first part, which comprises the size range of 50450 microns, is made of pure $2 \mathrm{D}-\mathrm{S}$ distributions $\left(N_{2 \mathrm{D}-\mathrm{S}}\right)$, whereas the third part between 950-6400 microns is purely taken from PIP ( $\left.N_{\text {PIP }}\right)$ distributions. The intermediate second part is obtained by weighting the 2D-S and PIP distributions with a transfer function (Eq. 3) which increases the weight of the PIP and decreases the weight of the 2D-S data with increasing $D_{\max }$. The bin resolution of the composite distributions is given by $\Delta D_{\max }$ equal to 10 microns. Examples of PSD and AsD are presented in Fig. 2. Figure 2a shows the PSD composite distribution and the individual PSD of the individual probes. The AsD composite distribution is shown in Fig. 2b. It can be seen that the transfer function smoothes the transition from the 2D-S to the PIP. In the common size range [ $450 \mu \mathrm{m} ; 950 \mu \mathrm{m}$ ] the two probes $2 \mathrm{D}-\mathrm{S}$ and PIP are in rather good agreement. The $2 \mathrm{D}-\mathrm{S}$ is most reliable and performing well up to particle sizes of $500 \mu \mathrm{m}$, beyond the 2D-S starts to be slowly affected by the truncation of the particles. This is why 2D-S images are taken into account with decreasing weight in the common size range [450 $\mu \mathrm{m} ; 950 \mu \mathrm{m}]$. In contrast, the PIP is rather reliable beyond $900 \mu \mathrm{m}$. Below $900 \mu \mathrm{m}$, the PIP particles are taken into account with increasing weight, in order to ensure the continuity of the composite PSD calculated from 2D-S and PIP probe images. PSD (also AsD) and RASTA reflectivities are synchronized and averaged over the same time step of $5 \mathrm{~s}$ (for better PSD statistics). RASTA reflectivities measured $300 \mathrm{~m}$ below (nadir) and $300 \mathrm{~m}$ above the aircraft (zenith) along the flight trajectory are linearly interpolated to estimate the radar reflectivity at flight level. The uncertainty of the radar reflectivity is about $2 \mathrm{dBZ}$, which takes into account measurement uncertainties and an eventual calibration error. For the MT data set it was calculated that the mean reflectivity difference between $300 \mathrm{~m}$ above and below the plane is in the order of $3 \mathrm{dBZ}$, which means a reflectivity difference between flight
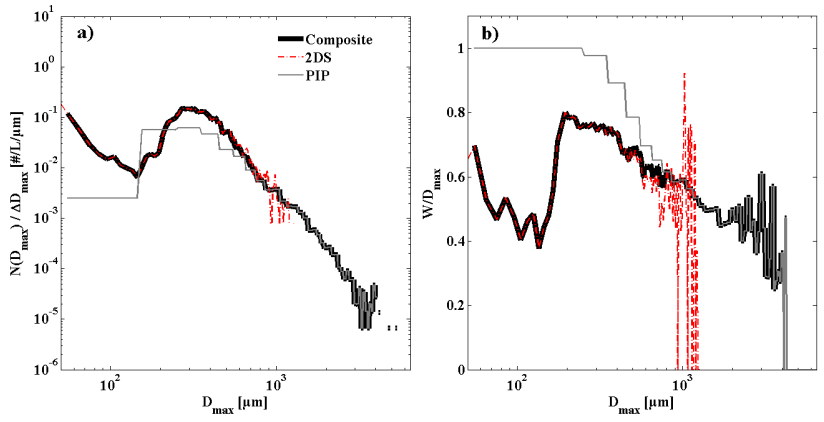

Figure 2. (a) Number size distributions (as a function of $D_{\max }$ ) of cloud particles. The dashed red line represents the $2 \mathrm{D}-\mathrm{S}$ data, the grey line the PIP data, and the bold black line represents the composite particle number size distribution (PSD). (b) Aspect ratio of 2-D particles as a function of $D_{\max }$. Symbols for 2D-S and PIP as above. All curves (number size distributions and aspect ratios) represent an average over 5 seconds of measurements.

level and $300 \mathrm{~m}$ above or below of about $1.5 \mathrm{dBZ}$. This is less than the calibration and measurement error. Furthermore, the uncertainty in the measured concentrations of hydrometeors is estimated by the probe suppliers to be $20 \%$. This uncertainty stems mainly from the calculations of the sampling volume.

\section{Methodology of $m(D)$ retrieval: studying 2-D and 3-D aspects of hydrometeors}

\subsection{Simulations of artificial ice crystal shapes and associated $S(D)$ and $m(D)$}

Optical array probes (OAPs) measure the shadow projection of 3-D cloud particles on a 2-D plan. Theoretical simulations of 3-D crystals were processed, and are described in more detail in Appendix A. The corresponding 2-D projections are based on the principle of randomly oriented 3-D particles projected on a 2-D plan. These 2-D images are processed with the same algorithm used for real particle images in order to deduce particle projected area $\mathrm{Sp}$ and maximum diameter $D_{\max }$ of each random projection. Overall, 45 different kind of hydrometeors (or habits) were simulated and tested. Figure 3 shows some examples of arbitrarily oriented 3-D crystals (stellar, columns, plates, capped columns, rosettes, and aggregates thereof) that were projected onto a plan. For each habit type numerous simulations and orientations are performed, then the projected surface $\mathrm{Sp}$ is fitted as a function of $D_{\max }$ (the relation is denoted $S(D)$; Eq. 4), and likewise the mass is fitted as a function of $D_{\max }$ (see Eq. 1).

$S\left(D_{\max }\right)=\gamma \times D_{\max }^{\sigma}$

We assume random orientation, where each orientation has the same probability, and therefore not consider any possible effect of predominant orientation of hydrometeors during 


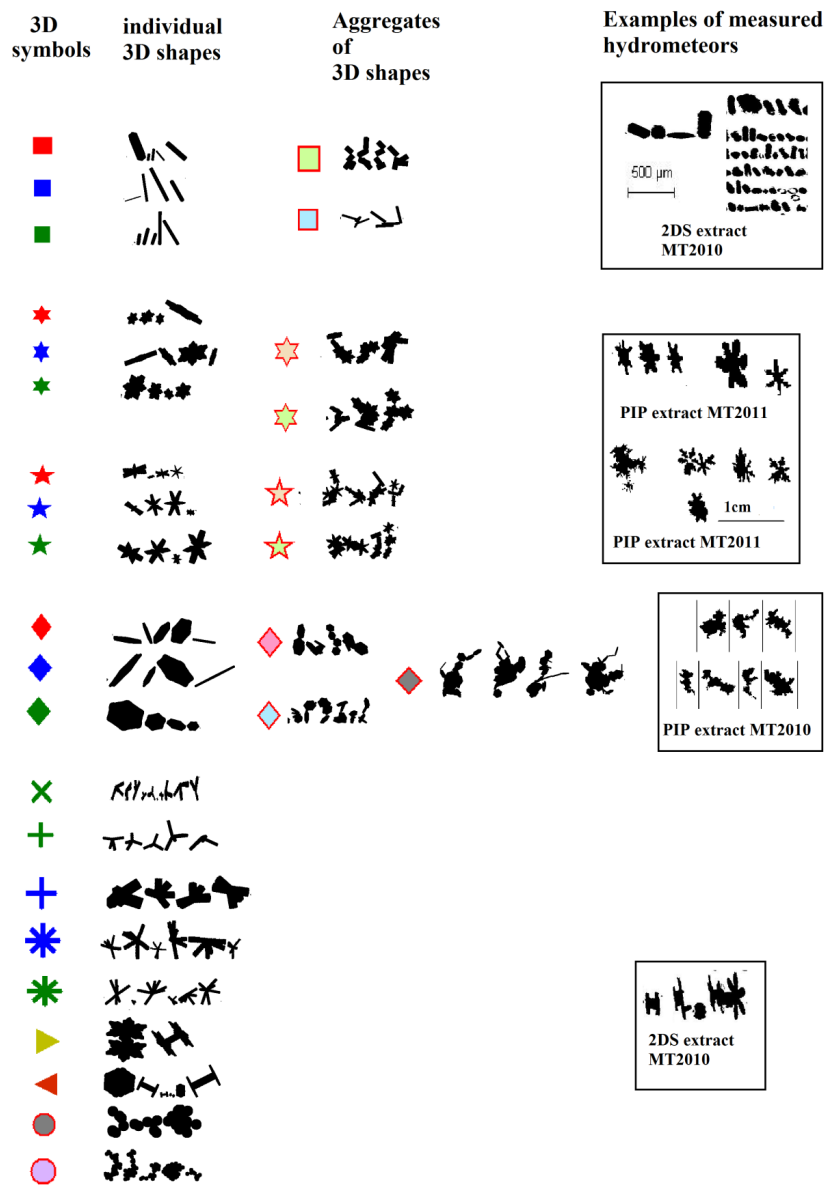

Figure 3. To the left are presented examples of 2-D projections of randomly oriented individual 3-D shapes (single hydrometeors) with their corresponding symbols as they are used in subsequent Fig. 4 and in Table 2. In the middle column are shown examples of aggregates composed of respective single individual shapes to the left. The right column shows examples of measured natural crystals resembling more or less the 3-D simulations with respective projections.

sampling. Probes are mounted under the wings at a distance of approximatively $0.5 \mathrm{~m}$, in addition, the probe tips exceed the wing leading edge. Deviations in exponents $\sigma$ and $\beta$ are further discussed in Appendix A. We assume extreme orientations for different habits, and analyze uncertainties of $S(D)$ and $m(D)$ relationships due to possible orientation of ice crystals.

Relationships $S(D)$ and $m(D)$ for each type of habit are fitted with power laws (Eqs. 1 and 4). The resulting exponents $\sigma$ for $S(D)$ and $\beta$ for $m(D)$ are shown in Fig. 4 and reported in Table 2. In order to compare with existing values of $\sigma$ and $\beta$ found in the literature, we have added the values given in M96. In addition, Table 2 summarizes the values and the associated symbols of each simulated particle habit. The linear relationship fitted for $\beta$ related to $\sigma$ for 45 simulated habits is presented in Eq. (5), which is valid for $\sigma$ in the range

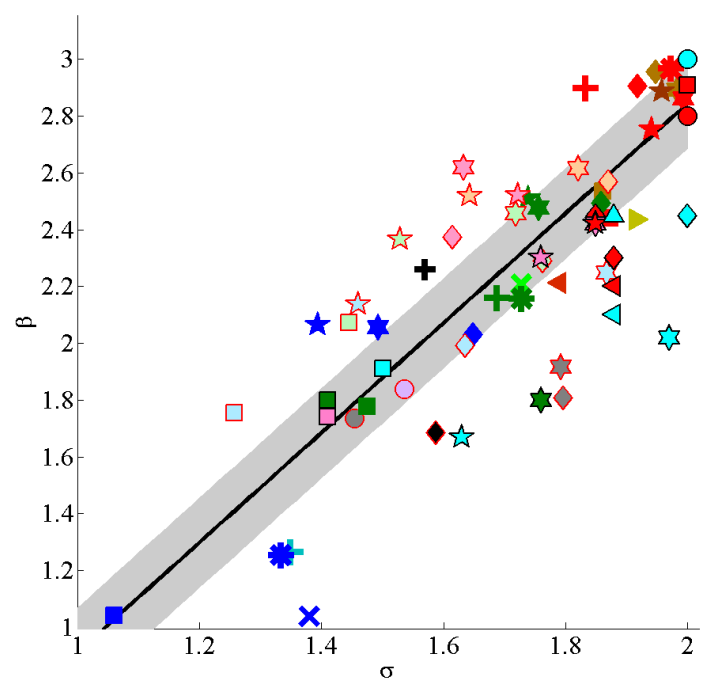

Figure 4. Exponent $\beta$ of the the $m(D)$ relationship as a function of the exponent $\sigma$ of the $S(D)$ relationship. All data points either with red contours or without contours were deduced for a population of 1000 simulated 3-D shapes and corresponding projections. Symbols with red contours are deduced for 3-D aggregates of crystals of an elementary shape. Symbols with black contours stem from M96. The legend for symbols is given in Table 2. A linear fit of all simulated data is shown by the black line. The grey band represents the mean standard deviation $( \pm 0.16)$.

[1.05;2], yielding values for $\beta$ in the range [1;2.94].

$\beta_{\sigma}( \pm 0.16)=1.93 \cdot \sigma-1.02$

There is no evidence of such a fit, neither in literature, nor in theory. From the obtained results one can notice that varying the linear ratio between $H$ and $L$ for plates (also valid for slender stellars, solid stellars, and rosettes) does not impact significantly $\sigma$ and $\beta$, whereas a nonlinear ratio $H=\sqrt{L}$ has more impact on both exponents. The latter case produces results closer to measurements presented by M96 (Tab. 2), with simulations from our study resulting in $\sigma=1.86$ and $\beta=2.49$ and M96 measurements resulting in $\sigma=1.85$ (for $D_{\max }<100 \mu \mathrm{m}$ ) and $\beta=2.45$, respectively. For $D_{\max }>100 \mu \mathrm{m}$, results are not readily comparable with the M96 results as in their study random orientation is not assumed. Regarding columns, an increase of the ratio $H / L$ has more impact on $\sigma$ and $\beta$. As stated for hexagonal plates, also for columns the nonlinear ratio $L=\sqrt{H}$ brings the simulations closer to the M96 measurements, with $\sigma=1.48$ and $\beta=1.78$ for simulations (this study) and $\sigma=1.41$ and $\beta=1.74$ for the M96 measurements. Other habits from the M96 measurements are not comparable to our simulations.

In view of the results produced by the 3-D simulations, it seems that $\beta$ (and also $\sigma$ ) does not relate much to the sphericity of the crystal shape, but more to how a population of ice crystals is growing in the 3-D space (axis $x, y, z$ ) as a function of its evolution in direction of its maximum length. The 
Table 2. Ice crystal types and corresponding exponents $\sigma$ and $\beta$ of $S(D)$ and $m(D)$ relations. The symbols in the left column are subsequently used in Fig. 4 for individual ice crystal shapes. The first part of the table stems from Mitchell (1996) where random orientation is assumed for particles with $D_{\max }<100 \mu \mathrm{m}$ and horizontal orientation is assumed for particles beyond $100 \mu \mathrm{m}$. The second part of the table stems from simulations.

\begin{tabular}{|c|c|c|c|c|}
\hline symbol & Description & Range & $\sigma$ & $\beta$ \\
\hline \multicolumn{5}{|c|}{ Ice crystal shapes from Mitchell (1996) } \\
\hline & hexagonal plates & $15 \mu \mathrm{m}<D_{\max }<100 \mu \mathrm{m}$ & 1.85 & 2.45 \\
\hline & hexagonal plates & $100<D_{\max }<3000 \mu \mathrm{m}$ & 2 & 2.45 \\
\hline & hexagonal columns & $30<D_{\max }<100 \mu \mathrm{m}$ & 2 & 2.91 \\
\hline & hexagonal columns & $100<D_{\max }<300 \mu \mathrm{m}$ & 1.5 & 1.91 \\
\hline & hexagonal columns & $D_{\max }>300 \mu \mathrm{m}$ & 1.41 & 1.74 \\
\hline & rimed long columns & $200<D_{\max }<2400 \mu \mathrm{m}$ & 1.41 & 1.8 \\
\hline & crystals with sector-like branches $(\mathrm{P} 1 \mathrm{~b})$ & $10<D_{\max }<40 \mu \mathrm{m}$ & 1.85 & 2.42 \\
\hline & crystals with sector-like branches $(\mathrm{P} 1 \mathrm{~b})$ & $40<D_{\max }<2000 \mu \mathrm{m}$ & 1.97 & 2.02 \\
\hline & broad-branched crystals (Plc) & $10<D_{\max }<100 \mu \mathrm{m}$ & 1.85 & 2.42 \\
\hline & broad-branched crystals (Plc) & $100<D_{\max }<1000 \mu \mathrm{m}$ & 1.76 & 1.8 \\
\hline & stellar crystals with broad arms (P1d) & $10<D_{\max }<90 \mu \mathrm{m}$ & 1.85 & 2.42 \\
\hline & stellar crystals with broad arms (P1d) & $90<D_{\max }<1500 \mu \mathrm{m}$ & 1.63 & 1.67 \\
\hline & densely rimed dendrites (R2b) & $1800<D_{\max }<4000 \mu \mathrm{m}$ & 1.76 & 2.3 \\
\hline & side planes (S1) & $300<D_{\max }<2500 \mu \mathrm{m}$ & 1.88 & 2.3 \\
\hline & bullet rosettes, five branches at $-42^{\circ} \mathrm{C}$ & $200<D_{\max }<1000 \mu \mathrm{m}$ & 1.57 & 2.26 \\
\hline & aggregates of side planes & $600<D_{\max }<4100 \mu \mathrm{m}$ & 1.88 & 2.2 \\
\hline & aggregates of side planes, columns \& bullets (S3) & $800<D_{\max }<4500 \mu \mathrm{m}$ & 1.88 & 2.1 \\
\hline & assemblies of planar poly-crystals in cirrus clouds & $20<D_{\max }<450 \mu \mathrm{m}$ & 1.88 & 2.45 \\
\hline & lump graupel (R4b) & $500<D_{\max }<3000 \mu \mathrm{m}$ & 2 & 2.8 \\
\hline & hail & $5000<D_{\max }<25000 \mu \mathrm{m}$ & 2 & 3 \\
\hline \multicolumn{5}{|c|}{ Simulations of ice crystal shapes } \\
\hline & columns $\left(H=5^{*} L\right)$ & $100<D_{\max }<1000 \mu \mathrm{m}$ & 1.86 & 2.53 \\
\hline & columns $(H=10 * L)$ & $100<D_{\max }<1000 \mu \mathrm{m}$ & 1.87 & 2.44 \\
\hline & columns $(L=160 \mu \mathrm{m})$ & $100<D_{\max }<1000 \mu \mathrm{m}$ & 1.06 & 1.04 \\
\hline & columns $(L=\sqrt{H})$ & $100<D_{\max }<1000 \mu \mathrm{m}$ & 1.48 & 1.78 \\
\hline & thick star $\left(H=0.2^{*} L\right)$ & $200<D_{\max }<1200 \mu \mathrm{m}$ & 1.98 & 2.89 \\
\hline & thick star $\left(H=0.1^{*} L\right)$ & $200<D_{\max }<1200 \mu \mathrm{m}$ & 1.99 & 2.86 \\
\hline & thick stars $(H=40 \mu \mathrm{m})$ & $200<D_{\max }<1200 \mu \mathrm{m}$ & 1.49 & 2.06 \\
\hline & thick stars $(H=\sqrt{L})$ & $200<D_{\max }<1200 \mu \mathrm{m}$ & 1.76 & 2.48 \\
\hline & thin stars $(H=0.2 * L)$ & $100<D_{\max }<1000 \mu \mathrm{m}$ & 1.96 & 2.89 \\
\hline & thin stars $(H=0.1 * L)$ & $100<D_{\max }<1000 \mu \mathrm{m}$ & 1.94 & 2.75 \\
\hline & thin stars $(H=40 \mu \mathrm{m})$ & $100<D_{\max }<1000 \mu \mathrm{m}$ & 1.39 & 2.06 \\
\hline & thin stars $(H=\sqrt{L})$ & $100<D_{\max }<1000 \mu \mathrm{m}$ & 1.74 & 2.51 \\
\hline & plates $(H=0.2 * L)$ & $200<D_{\max }<2000 \mu \mathrm{m}$ & 1.95 & 2.96 \\
\hline & plates $(H=0.1 * L)$ & $200<D_{\max }<2000 \mu \mathrm{m}$ & 1.92 & 2.91 \\
\hline & plates $(H=40 \mu \mathrm{m})$ & $200<D_{\max }<2000 \mu \mathrm{m}$ & 1.65 & 2.03 \\
\hline & plates $(H=\sqrt{L})$ & $200<D_{\max }<2000 \mu \mathrm{m}$ & 1.86 & 2.49 \\
\hline & rosettes $\left(L=50 \mu \mathrm{m} ; N_{\max }=3\right)$ & $50<D_{\max }<500 \mu \mathrm{m}$ & 1.37 & 1.04 \\
\hline 2 & rosettes $\left(L=\sqrt{H} ; N_{\max }=3\right)$ & $50<D_{\max }<500 \mu \mathrm{m}$ & 1.69 & 2.21 \\
\hline
\end{tabular}


Table 2. Continued.

\begin{tabular}{|c|c|c|c|c|}
\hline 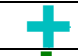 & rosettes $\left(L=100 \mu \mathrm{m} ; N_{\max }=4\right)$ & $100<D_{\max }<1000 \mu \mathrm{m}$ & 1.39 & 1.26 \\
\hline & rosettes $\left(L=\sqrt{H} ; N_{\max }=4\right)$ & $100<D_{\max }<1000 \mu \mathrm{m}$ & 1.65 & 2.16 \\
\hline & rosettes $\left(L=0.5 \mathrm{H} ; N_{\max }=5\right)$ & $500<D_{\max }<2000 \mu \mathrm{m}$ & 1.83 & 2.9 \\
\hline & rosettes $\left(L=0.25 \mathrm{H} ; N_{\max }=6\right)$ & $500<D_{\max }<2500 \mu \mathrm{m}$ & 1.78 & 2.97 \\
\hline & $\operatorname{rosettes}\left(L=100 \mu \mathrm{m} ; N_{\max }=6\right)$ & $100<D_{\max }<1000 \mu \mathrm{m}$ & 1.42 & 1.25 \\
\hline & rosettes $\left(L=\sqrt{H} ; N_{\max }=6\right)$ & $100<D_{\max }<1000 \mu \mathrm{m}$ & 1.66 & 2.16 \\
\hline & capped columns ( 2 thick stars: $\mathrm{L}_{2}=2.5 \mathrm{~L}_{1} ; \mathrm{H}=\mathrm{L}_{1}$ ) & $150<D_{\max }<1400 \mu \mathrm{m}$ & 1.79 & 2.21 \\
\hline & capped columns ( 2 plates: $\mathrm{L}_{2}=2.5 \mathrm{~L}_{1} ; \mathrm{H}=\mathrm{L}_{1}$ ) & $150<D_{\max }<1400 \mu \mathrm{m}$ & 1.92 & 2.43 \\
\hline$\Sigma$ & $\begin{array}{l}\qquad 8<N_{\mathrm{agg}}<30 \text { thick stars }(H=\sqrt{L}) \\
\text { individual diameter such : } 300<L<400 \mu \mathrm{m}\end{array}$ & $1000<D_{\max }<4000$ & 1.79 & 1.92 \\
\hline & $\begin{array}{l}\qquad 8<N_{\mathrm{agg}}<30 \text { plates }\left(H=0.1^{*} L\right) \\
\text { individual diameter such : } 200<L<300 \mu \mathrm{m}\end{array}$ & $600<D_{\max }<2000$ & 1.8 & 1.81 \\
\hline & $\begin{array}{l}\qquad 8<N_{\text {agg }}<30 \text { plates }(H=\sqrt{L}) \\
\text { individual diameter such : } 200<L<300 \mu \mathrm{m}\end{array}$ & $600<D_{\max }<2500$ & 1.59 & 1.69 \\
\hline & $\begin{array}{l}\quad 2<N_{\mathrm{agg}}<4 \text {; columns }(L=160 \mu \mathrm{m}) \\
\text { individual diameter such : } 400<H<600\end{array}$ & $400<D_{\max }<1500$ & 1.26 & 1.75 \\
\hline & $\begin{array}{l}\qquad 2<N_{\mathrm{agg}}<4 ; \text { columns }(L=\sqrt{H}) \\
\text { individual diameter such : } 400<H<600\end{array}$ & $200<D_{\max }<1000$ & 1.45 & 2.07 \\
\hline & $\begin{array}{l}\quad 2<N_{\mathrm{agg}}<4 \text {; thick stars }(H=0.2 * L) \\
\text { individual diameter such : } 400<L<600 \mu \mathrm{m}\end{array}$ & $400<D_{\max }<3000$ & 1.82 & 2.62 \\
\hline & $\begin{array}{l}\qquad 2<N_{\mathrm{agg}}<4 \text {; thick stars }(\mathrm{H}=0.1 * \mathrm{~L}) \\
\text { individual diameter such : } 400<L<600 \mu \mathrm{m}\end{array}$ & $400<D_{\max }<3000$ & 1.63 & 2.62 \\
\hline & $\begin{array}{l}\qquad 2<N_{\mathrm{agg}}<4 ; \text { thick stars }(\mathrm{H}=40 \mu \mathrm{m}) \\
\text { individual diameter such : } 400<L<600 \mu \mathrm{m}\end{array}$ & $400<D_{\max }<3000$ & 1.87 & 2.25 \\
\hline$\sum_{\gamma}$ & $\begin{array}{l}\qquad 2<N_{\text {agg }}<4 ; \text { thick stars }(H=\sqrt{L}) \\
\text { individual diameter such : } 400<L<600 \mu \mathrm{m}\end{array}$ & $400<D_{\max }<3000$ & 1.72 & 2.46 \\
\hline$\sum$ & $\begin{array}{l}\qquad 2<N_{\mathrm{agg}}<4 ; \text { thin stars }(\mathrm{H}=0.2 * \mathrm{~L}) \\
\text { individual diameter such : } 300<L<600 \mu \mathrm{m}\end{array}$ & $300<D_{\max }<2000$ & 1.64 & 2.52 \\
\hline 负 & $\begin{array}{l}\qquad 2<N_{\mathrm{agg}}<4 ; \text { thin stars }(\mathrm{H}=0.1 * \mathrm{~L}) \\
\text { individual diameter such }: 300<L<500 \mu \mathrm{m}\end{array}$ & $300<D_{\max }<1500$ & 1.72 & 2.52 \\
\hline 怂 & $\begin{array}{l}\qquad 2<N_{\text {agg }}<4 ; \text { thin stars }(H=40 \mu \mathrm{m}) \\
\text { individual diameter such : } 300<L<500 \mu \mathrm{m}\end{array}$ & $300<D_{\max }<1500$ & 1.46 & 2.14 \\
\hline 岕 & $\begin{array}{l}\quad 2<N_{\mathrm{agg}}<4 ; \text { thin stars }(H=\sqrt{L}) \\
\text { individual diameter such : } 300<L<500 \mu \mathrm{m}\end{array}$ & $300<D_{\max }<2000$ & 1.53 & 2.37 \\
\hline & $\begin{array}{l}\qquad 2<N_{\mathrm{agg}}<4 \text {; plates }(H=0.2 * L) \\
\text { individual diameter such }: 300<L<500 \mu \mathrm{m}\end{array}$ & $300<D_{\max }<2000$ & 1.87 & 2.57 \\
\hline & $\begin{array}{l}\qquad 2<N_{\text {agg }}<4 ; \text { plates }(\mathrm{H}=0.1 * \mathrm{~L}) \\
\text { individual diameter such : } 300<\mathrm{L}<500 \mu \mathrm{m}\end{array}$ & $300<D_{\max }<1500$ & 1.61 & 2.37 \\
\hline & $\begin{array}{l}\quad 2<N_{\mathrm{agg}}<4 ; \text { plates }(\mathrm{H}=40 \mu \mathrm{m}) \\
\text { individual diameter such }: 300<\mathrm{L}<500 \mu \mathrm{m}\end{array}$ & $300<D_{\max }<1500$ & 1.64 & 1.99 \\
\hline & $\begin{array}{l}\qquad 2<N_{\mathrm{agg}}<4 ; \text { plates }(H=\sqrt{L}) \\
\text { individual diameter such }: 300<\mathrm{L}<600 \mu \mathrm{m}\end{array}$ & $300<D_{\max }<1500$ & 1.76 & 2.29 \\
\hline & $\begin{array}{l}\quad 3<N_{\text {agg }}<20 ; \text { spheres } \\
\text { individual diameter such : } \mathrm{D}=60 \mu \mathrm{m} ;\end{array}$ & $200<D_{\max }<2000 \mu \mathrm{m}$ & 1.45 & 1.74 \\
\hline$C$ & $\begin{array}{c}3<N_{\mathrm{agg}}<50 ; \text { spheres } \\
\text { individual diameter such : } \mathrm{D}=150 \mu \mathrm{m} ;\end{array}$ & $100<D_{\max }<1000 \mu \mathrm{m}$ & 1.54 & 1.84 \\
\hline
\end{tabular}




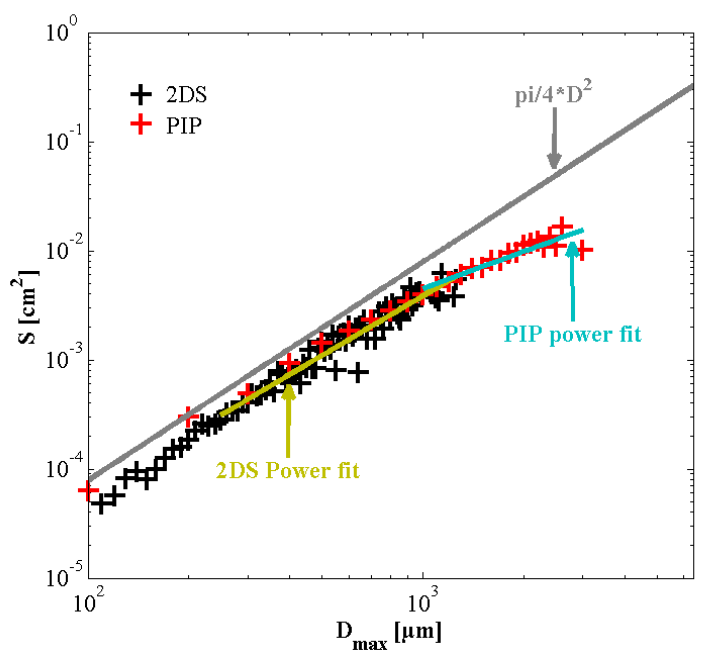

Figure 5. Mean projected surface versus $D_{\max }$. Black symbols represent the 2D-S image data and red symbols the PIP data. The grey line would be the power law fit for spherical particles. The golden line is the power law which fits the $2 \mathrm{D}-\mathrm{S}$ data for $D_{\max }$ larger than $250 \mu \mathrm{m}$ and the blue line fits the PIP data with a power law for $D_{\max }$ larger than $950 \mu \mathrm{m}$.

behavior of the exponent $\beta$ for plates and stellars but also for rosettes shows that, if the crystal height grows at the same speed as the length (which is a combination of the growth on two axes), then $\beta$ is close to 3 . In contrast, if the growth in length is 2 times larger than the height, then $\beta$ is closer to 2.5 . Finally, if the height remains constant while the length is growing, then $\beta$ gets close to 2 .

\subsection{Surface-diameter relationships of natural hydrometeors}

This section focuses on the $S(D)$ relationship (see Eq. 4) and also on the correlation which exists between $D_{\max }, \mathrm{Sp}$, and the mass of hydrometeors. Since ice crystals have complex and varied shapes, the description of their volume (or mass) and their projected area $\mathrm{Sp}$ as a function of the particle diameter cannot be described unambiguously with constant $\sigma$ exponents (for $S(D)$ ) or $\beta$ (for $m(D)$ ). In this study, $S(D)$ power law relations are calculated for $5 \mathrm{~s}$ steps and are synchronized with PSD and RASTA reflectivity. To calculate $S(D)$, we plot the mean $\mathrm{Sp}$ of the particles vs. their $D_{\max }$ (Fig. 5) for the two probes. Sp are averaged by bins in order to get $S(D)$ independently of the ice crystals concentration. $S(D)$ relations are then fitted by a power law described by $\gamma$ and $\sigma$, for both probes, respectively. On a log-log scale, $\ln (\gamma)$ represents the y-axis intercept and $\sigma$ the slope of the linear relationship such that $\log (S)=\sigma \cdot \ln (D)+\ln (\gamma)$. $S(D)$ relationships for the 2D-S and PIP probes are calculated using particles larger than 250 and $950 \mu \mathrm{m}$, respectively. As shown in Fig. 5 S-D relationships calculated for submillimetric (2D-S) and millimetric particles (PIP) can deviate.

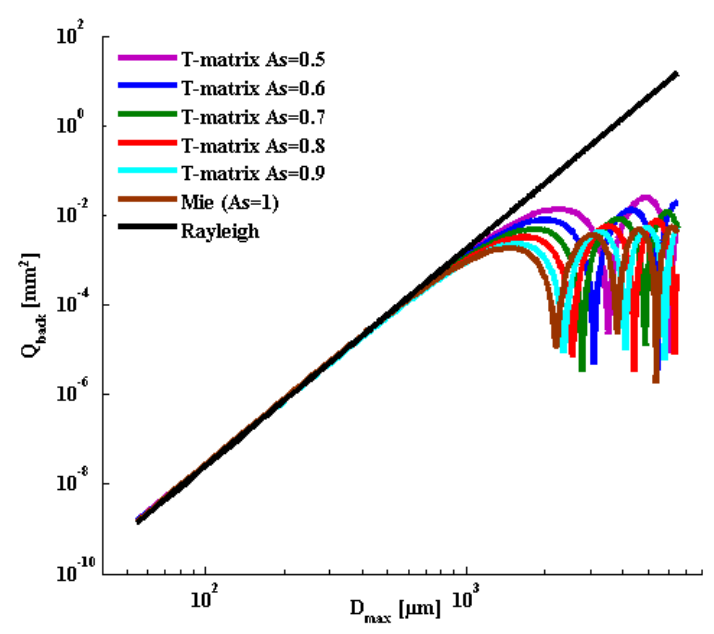

Figure 6. Calculated backscattering cross section as a function of the maximum particle diameter $D_{\max }$. Pink, blue, green, red and cyan curves are calculated for different Aspect ratios by the T-matrix method, whereas the brown curve is based on the Mie theory calculation for a spherical particle. The black curve represents the Rayleigh approximation.

One can suppose that when $S(D)$ of 2D-S and PIP are different, this implies to use $\sigma$ deduced from the 2D-S images $\left(\sigma_{2 \mathrm{D}-\mathrm{S}}\right)$ to calculate the $\beta$ exponent for sub millimetric particles $\left(\beta_{2 \mathrm{D}-\mathrm{S}}\right)$ and $\sigma$ deduced from the PIP images $\left(\sigma_{\mathrm{PIP}}\right)$ to calculate the $\beta$ exponent for the super-millimetric particles $\left(\beta_{\text {PIP }}\right)$. Then CWC would be calculated as follows:

$$
\begin{aligned}
& \mathrm{CWC}=\sum_{D_{\max }=55 \mu \mathrm{m}}^{D_{\max }=D c} N\left(D_{\max }\right) \cdot \alpha_{2 \mathrm{D}-\mathrm{S}} \cdot D_{\max }^{\beta_{2 \mathrm{D}-\mathrm{S}}} \cdot \Delta D_{\max } \\
& +\sum_{D_{\max }=D c}^{D_{\max }=6450} N(D \text { max }) \cdot \alpha_{\mathrm{PIP}} \cdot D_{\max }^{\beta_{\mathrm{PIP}}} \cdot \Delta D_{\max } .
\end{aligned}
$$

Having fixed $\beta_{2 \mathrm{D}-\mathrm{S}}$ and $\beta_{\mathrm{PIP}}$ would still mean that when constraining the pre-factor of the $m(D)$ relation, one needs to solve one equation with two unknowns for the two probes: $\alpha_{2 \mathrm{D}-\mathrm{S}}$ and $\alpha_{\text {PIP. }}$. Therefore, we introduce here a single $\sigma$ exponent taking into account images from 2D-S and PIP probes, in order to calculate the variability of the $m(D)$ coefficients from the variability of $S(D)$ relationships. 


$$
\begin{aligned}
& \sigma=\frac{\sum_{\max }^{950 \mu \mathrm{m}} N\left(D_{\max }\right) \cdot S\left(D_{\max }\right)}{6450 \mu \mathrm{m}} \cdot \sigma_{2 \mathrm{D}-\mathrm{S}} \\
& \sum_{D_{\max }=250 \mu \mathrm{m}} N\left(D_{\max }\right) \cdot S\left(D_{\max }\right)
\end{aligned}
$$

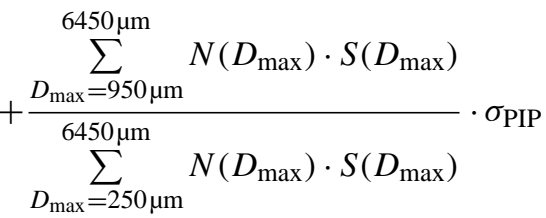

This particular $\sigma$ of Eq. (7) is calculated by weighting the exponent $\sigma$ of each probe $\left(\sigma_{2 \mathrm{D}-\mathrm{S}}, \sigma_{\mathrm{PIP}}\right)$ with the ratio of the surface of ice crystals contained in the size range of the individual probe (size range where individual $S(D)$ relationship is calculated) over the entire surface within the total size range covered by both probes.

\subsection{Mass-diameter coefficients and CWC retrieval}

In order to better understand the importance of coefficients $\alpha$ and $\beta$ in Eq. (1) and their impact on the retrieved CWC, reflectivity simulations at $94 \mathrm{GHz}$ were performed and compared with corresponding measured reflectivities along the flight trajectory. Simulations of radar reflectivities are complex when considering non-spherical ice crystals. Hogan et al. (2011), have used the Rayleigh-Gans approximation to simulate the reflectivity of ice hydrometeors interpreted as oblate spheroids (at 10 and $94 \mathrm{GHz}$ ). Therein a constant aspect ratio of 0.6 was assumed to describe the flattening of the spheroids. Applying the BF95 parameterization to calculate CWC, a good agreement was achieved between simulated and measured reflectivities.

In this study, backscatter properties of the hydrometeors were simulated with the T-matrix method (Mishchenko et al., 1996) for crystals and/or with Mie solution for spherical particles. In order to model the scattering properties of the ice particles, these particles are assumed to be oblate spheroids with a flattening that equals the mean aspect ratio $\overline{\mathrm{As}}$ of the hydrometeors with $D_{\max }<2 \mathrm{~mm}$, which impact most the simulated reflectivity:

$\overline{\mathrm{As}}=\sum_{D_{\max }=55 \mu \mathrm{m}}^{2000 \mu \mathrm{m}} \operatorname{Pi}\left(D_{\max }\right) \cdot A s\left(D_{\max }\right)$,

where the $\operatorname{Pi}\left(D_{\max }\right)$ is the weighting function and is calculated as follows:

$$
\operatorname{Pi}\left(D_{\max }\right)=\frac{N\left(D_{\max }\right) \cdot D_{\max }^{3} \cdot \Delta D_{\max }}{\sum_{D_{\max }=55 \mu \mathrm{m}}^{2000 \mu \mathrm{m}} N\left(D_{\max }\right) \cdot D_{\max }^{3} \cdot \Delta D_{\max }} .
$$

$N\left(D_{\max }\right)$ is the concentration of the hydrometeors in Liter per micrometer and $A s\left(D_{\max }\right)$ their aspect ratio, both functions of $D_{\max } . \overline{\mathrm{As}}$ is calculated every $5 \mathrm{~s}$ as is done for the

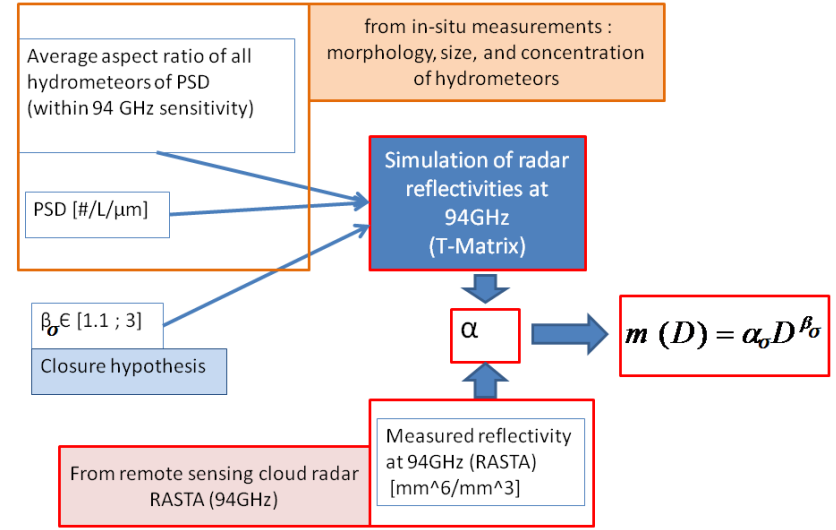

Figure 7. Implemented method to retrieve the coefficients (prefactor and exponent) of the mass-diameter relationship from the combination of radar reflectivity and 2-D hydrometeor images. Measured radar reflectivity and hydrometeor particle-size distributions and average aspect ratios serve as input for the $\mathbf{T}$-matrix method used for reflectivity simulations for variable $\beta_{\sigma}$ exponents. Closure hypothesis between measured and simulated reflectivities then yield the pre-factor $\alpha_{\sigma}$.

composite PSD, $\sigma$, and radar reflectivity. Indeed at $94 \mathrm{GHz}$ the hydrometeors with $D_{\max }>2 \mathrm{~mm}$ are not invisible, but the increase of their backscattering cross section ( $Q_{\text {back }}$; Fig. 6$)$ as a function of their size is not sufficient taking into account the very small crystal concentrations beyond a few millimeters. Thus, they do not impact the simulated reflectivity. Figure 6 also shows the impact of $\overline{\mathrm{As}}$ on the effective reflectivity for $94 \mathrm{GHz}$, for $\overline{\mathrm{As}}$ varying between 0.5 and 1. For $\overline{\mathrm{As}}=1$ particles are spherical and therefore the Mie solution of the Maxwell's equation can be used. For diameters less than 600-900 $\mu \mathrm{m}$ simulated radar reflectivities agree well with those calculated using the Rayleigh approximation. As it can be seen in this figure, the so-called "Mie effects" appear only for larger diameters and decreasing aspect ratio $\overline{\mathrm{As}}$. The $\operatorname{Pi}\left(D_{\max }\right)$ weighting function impacts the mean aspect ratio $\overline{\mathrm{As}}$ which will be subsequently used to constrain the T-matrix simulations of the radar reflectivity. $\operatorname{In} \mathrm{Pi}\left(D_{\max }\right)$ the maximum length of hydrometeors is taken at its third order, to take into account the impact of the hydrometeors in the sampling volume. This choice is a compromise to accomplish for the lack of knowledge to constrain the variability of $Q_{\text {back }}$ for natural ice crystals and previous approximations using the Mie solution to model $Q_{\text {back }}$. Instead of the third order of $D_{\max }$, we could have chosen the number concentration $N\left(D_{\max }\right)$ or $N\left(D_{\max }\right) \cdot S\left(D_{\max }\right)$, both may overestimate the smallest ice crystals, while $D_{\max }^{6}$ (Rayleigh approximation) does not seem to be the best choice either in this context.

In general, we consider hydrometeors as a homogeneous mixture of ice and/or air. In order to identify cases where the mixed phase (ice and water) was present, signals of the Rosemount ice detector (RICE) were analyzed. The RICE probe is in fact a supercooled water detector. Few and extremely 


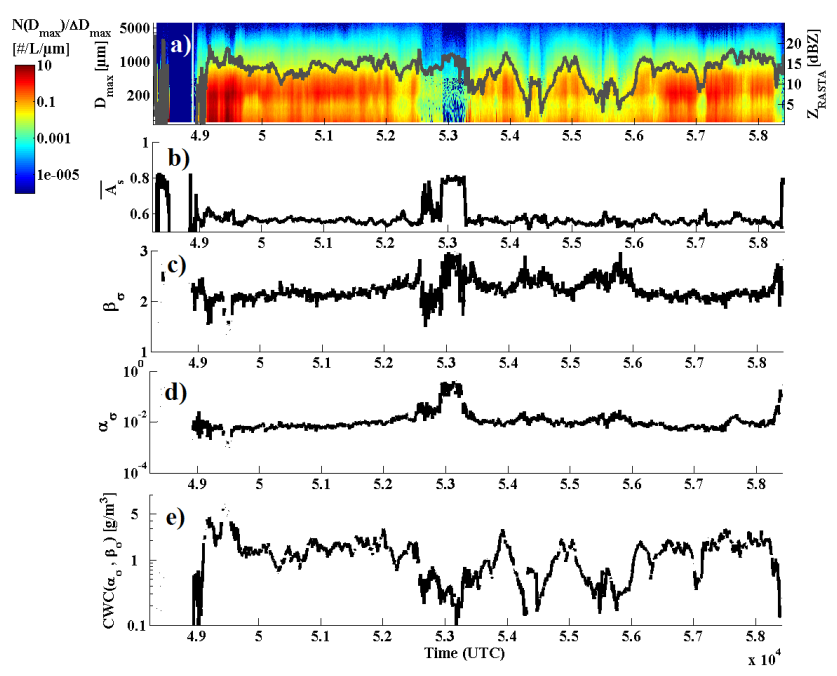

Figure 8. (a) Contour plot of the time series of the number PSD (as a function of $D_{\max }$ ) color coded with the number concentration, the grey line shows the simultaneously measured radar reflectivity (secondary $y$ axis). (b) Mean aspect ratio along the flight. (c) $\beta_{\sigma}$ exponent calculated from $\sigma$ according to Eqs. (5) and (7). (d) Pre-factor $\alpha_{\sigma}$, subsequently deduced with the T-matrix method. (e) CWC calculated with $\alpha_{\sigma}$ and $\beta_{\sigma}$ presented above.

short cases were identified where the RICE probe showed supercooled water. Data containing possible supercooled water were excluded from $m(D)$ calculations for ice.

The dielectric properties of ice particles are linked to the mass-diameter relationship characterized by the fraction of ice $f_{\text {ice }}$ (Eq. 10) in the hydrometeors. Equation (10) explains how the ice fraction of the solid hydrometeors are calculated, with $\rho_{\text {ice }}=0.917 \mathrm{~g} \mathrm{~cm}^{-3}$. The ice fraction $f_{\text {ice }}$ cannot exceed 1 .

$f_{\text {ice }}=\min \left(1, \frac{\alpha \cdot D_{\max }^{\beta}}{\frac{\pi}{6} \cdot \rho_{\text {ice }} \cdot D_{\max }^{3}}\right)$.

Once $f_{\text {ice }}$ is determined, the refractive index is calculated using the approximation of Maxwell Garnet (1904). The mass of the spheroid does not depend on the aspect ratio $\overline{\mathrm{As}}$, but the backscattering properties do. By means of the $\mathbf{T}$-matrix method the backscattering coefficient of a particle is calculated assuming the particle volume as an oblate spheroid with a diameter $D_{\mathbf{T}-\text { matrix }}$ :

$D_{\text {T-matrix }}=D_{\max } \cdot \sqrt[3]{\frac{1}{\mathrm{As}}}$.

In order to calculate the $94 \mathrm{GHz}$ radar reflectivity, the particle number distribution $N\left(D_{\max }\right)$, the mean aspect ratio $\overline{\mathrm{As}}$, the ice fraction $f_{\text {ice }}$ of the hydrometeors, and both the $\beta$ and $\alpha$ coefficients of the mass-diameter relation (Eq. 1) must be known or assumed. Figure 7 gives an outline of the technique developed to retrieve the $m(D)$ coefficients. After fixing $\beta_{\sigma}$
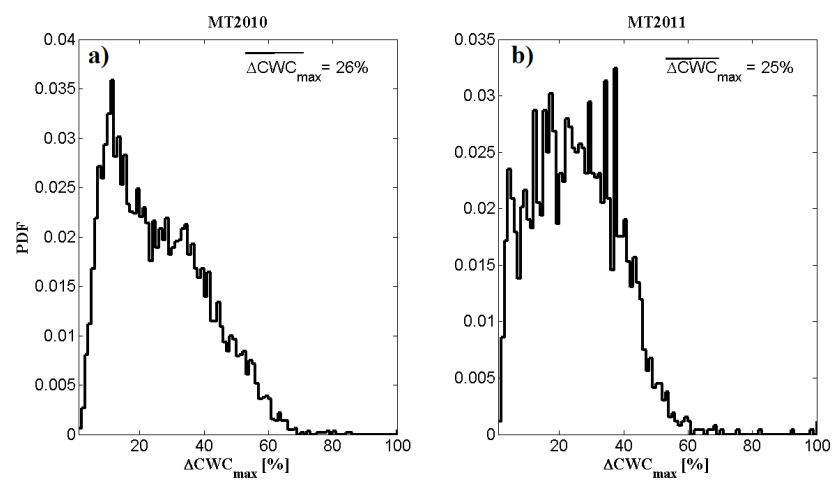

Figure 9. Histograms of the maximum deviation $(\Delta \mathrm{CWC} \max )$ on the retrieved CWC for (a) MT2010 and (b) MT2011.

from Eq. (5), then the prefactor $\alpha_{\sigma}$ is determined by minimizing the difference between the simulated and measured reflectivities. Then the corresponding CWC in $\mathrm{g} \mathrm{m}^{-3}$ is calculated from the PSD and the mass-diameter coefficients:

$\operatorname{CWC}\left(\alpha_{\sigma}, \beta_{\sigma}\right)=10^{3} \cdot \sum_{D_{\max } 50 \mu \mathrm{m}}^{D_{\max }=6400 \mu \mathrm{m}} N\left(D_{\max }\right)$

$: \alpha_{\sigma} D_{\max }^{\beta_{\sigma}} \cdot \Delta D_{\max }$.

Figure 8 shows the temporal evolution of the PSD, mean aspect ratio $\overline{\mathrm{As}}$, exponent $\beta_{\sigma}$, derived $\alpha_{\sigma}$, and calculated $\operatorname{CWC}\left(\alpha_{\sigma}, \beta_{\sigma}\right)$ for a cloud sequence of flight 18 during MT2010. The temporal variabilities of the PSD, $\overline{\mathrm{As}}$, the exponent $\beta_{\sigma}$, constrained pre-factor $\alpha_{\sigma}$, and CWC are considerable.

The uncertainty of this method is evaluated in systematically varying $\beta$ in the interval [1;3], while for each $\beta$ the pre-factor $\alpha$ is deduced accordingly by minimizing the difference between the simulated and measured reflectivities. Then the corresponding CWC values are calculated. For a given time step of $5 \mathrm{~s}$ the calculated minimum and maximum values of $\mathrm{CWC}\left(\mathrm{CWC}_{\min }\right.$ and $\mathrm{CWC}_{\max }$, respectively) are used to estimate the maximum uncertainty $\left(\Delta \mathrm{CWC}_{\max }\right)$ of the retrieved CWC. $\triangle \mathrm{CWC}_{\max }$ is defined as the maximum difference between $\operatorname{CWC}\left(\alpha_{\sigma}, \beta_{\sigma}\right)$ and the largest or smallest value of CWC. This maximum uncertainty can be also calculated in terms of the relative error in percent:

$$
\begin{aligned}
& 100 . \frac{\Delta \mathrm{CWC}_{\max }}{\operatorname{CWC}\left(\alpha_{\sigma}, \beta_{\sigma}\right)}=100 \times \\
& \frac{\operatorname{MAX}\left(\left[\left|\mathrm{CWC}_{\min }-\mathrm{CWC}\left(\alpha_{\sigma}, \beta_{\sigma}\right)\right| ;\left|\mathrm{CWC}_{\max }-\operatorname{CWC}\left(\alpha_{\sigma}, \beta_{\sigma}\right)\right|\right]\right)}{\operatorname{CWC}\left(\alpha_{\sigma}, \beta_{\sigma}\right)} .
\end{aligned}
$$

For both measurement campaigns MT2010 and MT2011, Fig. 9 shows the distribution of $\Delta \mathrm{CWC}_{\max }$ in percent. For most of the calculated CWC values the maximum errors remain below $30 \%$. Average values of the maximum deviations in CWC are $26 \%$ for MT2010 and 25\% for MT2011, respectively. 

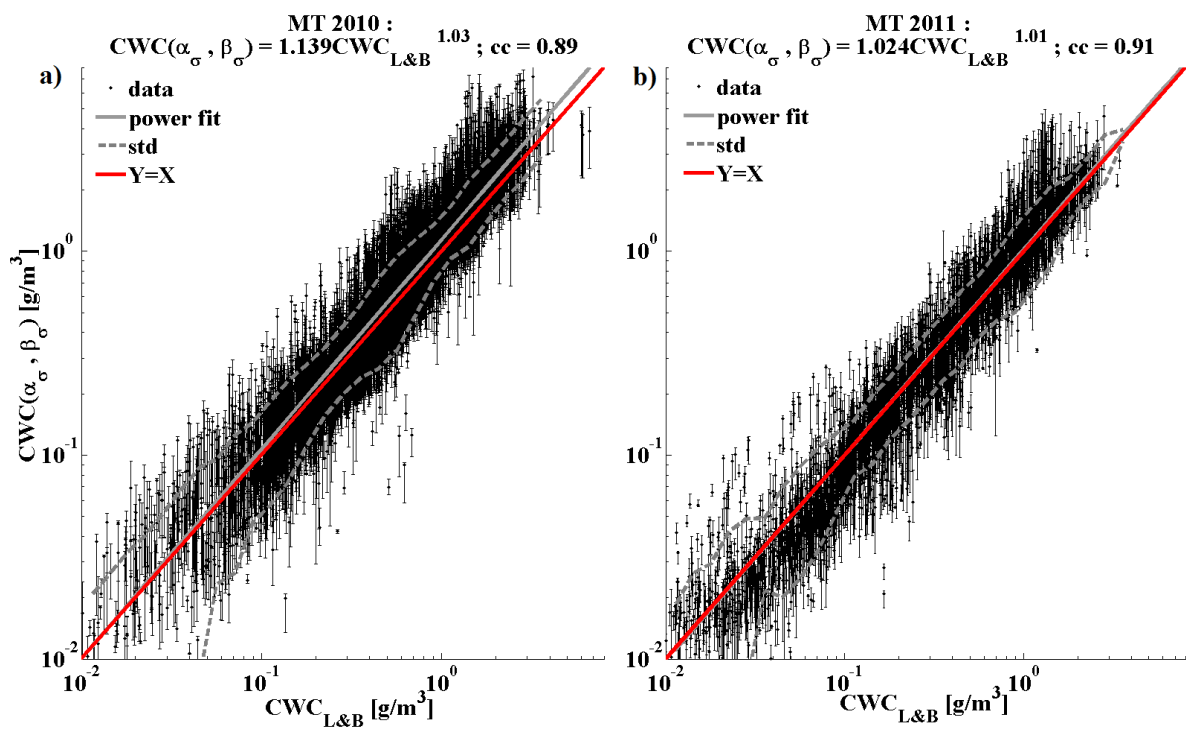

Figure 10. CWC $\left(\alpha_{\sigma}, \beta_{\sigma}\right)$ retrieved with T-matrix method including error bars versus $\mathrm{CWC}_{\mathrm{L} \& \mathrm{~B}}$ calculated from Baker and Lawson (2006) for (a) MT2010 and (b) MT2011. Error bars represent the minimum and the maximum of all possible CWC values, when $\beta$ varies between $[1 ; 3]$. The solid grey line represents a power law fit relating the two calculations. The dashed grey lines represent the standard deviation and the red line represents a $1: 1$ relation between $\mathrm{CWC}\left(\alpha_{\sigma}, \beta_{\sigma}\right)$ and $\mathrm{CWC}_{\mathrm{L} \& \mathrm{~B}}$.

$\mathrm{CWC}\left(\alpha_{\sigma}, \beta_{\sigma}\right)$ is compared with the $\mathrm{B} \& \mathrm{~L}$ scheme computing $\mathrm{CWC}_{\mathrm{B} \& \mathrm{~L}}$ from the 2-D images. This method was chosen among others because it does not require any assumption on particle habit and calculates the condensed mass particle by particle. Figure 10 shows calculated $\operatorname{CWC}\left(\alpha_{\sigma}, \beta_{\sigma}\right)$ vs. $\mathrm{CWC}_{\mathrm{B} \& \mathrm{~L}}$. The two CWC estimates are fitted using a power law. The exponent found is close to 1 which indicates that we are close to linearity between the two calculations for the two campaigns: 1.03 for MT2010 (Fig. 10a) and 1.01 for MT2011 (Fig. 10b). For MT2010 CWC $\left(\alpha_{\sigma}, \beta_{\sigma}\right)$ is $14 \%$ larger than $\mathrm{CWC}_{\mathrm{B} \& \mathrm{~L}}$, whereas for $\operatorname{MT} 2011 \mathrm{CWC}\left(\alpha_{\sigma}, \beta_{\sigma}\right)$ are close to $\mathrm{CWC}_{\mathrm{B} \& \mathrm{~L}}$. The data set of hydrometeors establishing the above $\mathrm{B} \& \mathrm{~L}$ scheme stems from winter storms in the central Sierra Nevada in the western part of the North American continent. The crystals were collected at the ground, and subsequently fitted to build the B\&L scheme. The B\&L scheme seems more appropriated to the MT2011 data set than the MT2010 data set. Comparisons between the two CWC retrieval methods also exhibit good correlation coefficients of 0.89 for MT2010 and 0.91 for MT2011, respectively. In addition, error bars for all analyzed CWC are given in Fig. 10 representing their minimum and maximum values which were determined using Eq. (13).

\subsection{Impact of measurement uncertainties on $m(D)$ and CWC retrieval}

This section quantifies the impact of the measurement uncertainties in radar reflectivity, $\overline{\mathrm{As}}, \beta$, PSD and also the probe shattering effect on the calculation of $\alpha$ and CWC. In order to quantify the impact of various measurement errors,
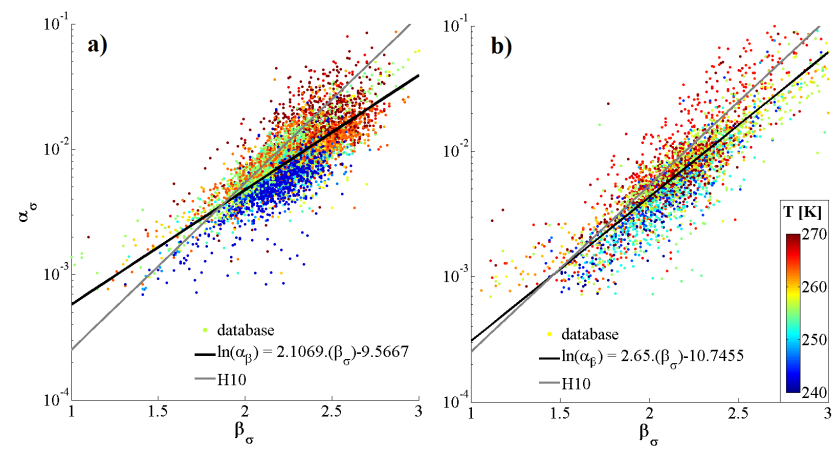

Figure 11. Scatter plot of exponent $\beta_{\sigma}$ as a function of $\alpha_{\sigma}$. Data points are color coded as a function of temperature; black lines represent power law fits. The grey lines represent added $m(D)$ power law fits for CRYSTAL-FACE data from H10. (a) MT2010 and (b) MT2011.

Table 3. Uncertainty of retrieved $\alpha$ and CWC as a function of the uncertainty of the measured reflectivity.

\begin{tabular}{lcc}
\hline$\Delta \mathrm{Z}[\mathrm{dBZ}]$ & $\Delta \alpha(\%)$ & $\Delta \mathrm{CWC}(\%)$ \\
\hline-2 & -26 & -26 \\
-1 & -12 & -12 \\
+1 & +11 & +11 \\
+2 & +21 & +21 \\
\hline
\end{tabular}

the retrieval of $\alpha$ and subsequent calculation of CWC were performed in shifting measured values by the amount of the respective measurement error. 
Table 4. Uncertainty of retrieved $\alpha$ and $\mathrm{CWC}$ as a function of the uncertainty of the average aspect ratio of 2-D images.

\begin{tabular}{lcc}
\hline$\Delta \overline{\mathrm{As}}(\%)$ & $\Delta \alpha(\%)$ & $\Delta \mathrm{CWC}(\%)$ \\
\hline-20 & -12 & -12 \\
-10 & -6 & -6 \\
+10 & +6 & +6 \\
+20 & +13 & +13
\end{tabular}

Table 5. Ratios of fitted $\alpha_{\beta}$ and $\alpha_{\beta, T}$ over retrieved $\alpha_{\sigma}$ from T-matrix calculations. Average ratios are given in column E. Quartile, median, third quartile, are given in $1 / 4,1 / 2$, and $3 / 4$ columns.

\begin{tabular}{lllll}
\hline & $\mathrm{E}$ & $1 / 4$ & $1 / 2$ & $3 / 4$ \\
\hline MT2010: $\alpha_{\beta} / \alpha_{\sigma}$ & 1.07 & 0.66 & 1.03 & 1.47 \\
MT2011: $\alpha_{\beta} / \alpha_{\sigma}$ & 1.03 & 0.54 & 0.95 & 1.53 \\
MT2010: $\alpha_{\beta, T} / \alpha_{\sigma}$ & 1.08 & 0.91 & 1.03 & 1.20 \\
MT2011: $\alpha_{\beta, T} / \alpha_{\sigma}$ & 0.99 & 0.74 & 0.92 & 1.13 \\
\hline
\end{tabular}

First, if reflectivity measured with the radar RASTA is shifted by $+2 \mathrm{dBZ}$, then CWC increases by about $21 \%$ (Table 3). Second, if the mean aspect ratio $\overline{\mathrm{As}}$ increases by $20 \%$ (due to a different calculation of the weighting function $\mathrm{Pi}$, for example as a function of $\left.N\left(D_{\max }\right)\right)$, then CWC increases by about $12 \%$ (Table 4$)$. Likewise, if $\mathrm{Pi}\left(D_{\max }\right)$ is calculated from $N\left(D_{\max }\right) \cdot S\left(D_{\max }\right)$, then $\overline{\mathrm{As}}$ increases by about $10 \%$ and CWC by about $6 \%$. Third, a decrease in $\beta_{\sigma}$ of -0.16 , leads to a decrease in $\alpha_{\sigma}$ of about $28 \%$ on average, whereas an increase in $\beta_{\sigma}$ of +0.16 increases the value of $\alpha_{\sigma}$ by about $42 \%$ on average. Fourth, in order to quantify the impact of particle shattering, $\alpha$ and CWC were calculated once without applying the removal algorithm. In this case the $S\left(D_{\max }\right)$ relationship is little impacted on average and the exponent $\beta_{\sigma}$ of $m\left(D_{\max }\right)$ increases slightly by approximately $+0.5 \%$. The retrieved prefactor $\alpha_{\sigma}$ is impacted by about $+4 \%$ and CWC increases by about $+5 \%$.

With respect to the concentration uncertainty $\Delta N$ when assuming an uncertainty in sampling volume of roughly $20 \%$ (uncertainty equally distributed over all sizes) we can estimate an uncertainty of $20 \%$ in $\alpha_{\sigma}$. While the reflectivity is not impacted by the measurement uncertainty on the PSD, the CWC which corresponds to this reflectivity is not impacted to. Then, the CWC calculation from two concentrations $\mathrm{N}_{1}$ and $\mathrm{N}_{2}$ which gives the same $\mathrm{CWC}$ can be expressed as it follows:

$\mathrm{CWC}=\int_{0}^{\infty} N_{1}(D) \cdot \alpha_{1} \cdot D^{\beta} \cdot \mathrm{d} D=\int_{0}^{\infty} N_{2}(D) \cdot \alpha_{2} \cdot D^{\beta} \cdot \mathrm{d} D$.

Furthermore, assuming that $\beta$ here is not impacted because the concentration uncertainty is assumed to be equally distributed over all diameters, then with $N_{1}(D)=\left(1 \pm \frac{\Delta N}{N}\right)$. $N_{2}(D)$ we can derive $\alpha_{1}=\left(1 \mp \frac{\Delta N}{N}\right) \cdot \alpha_{2}$, from where we con-

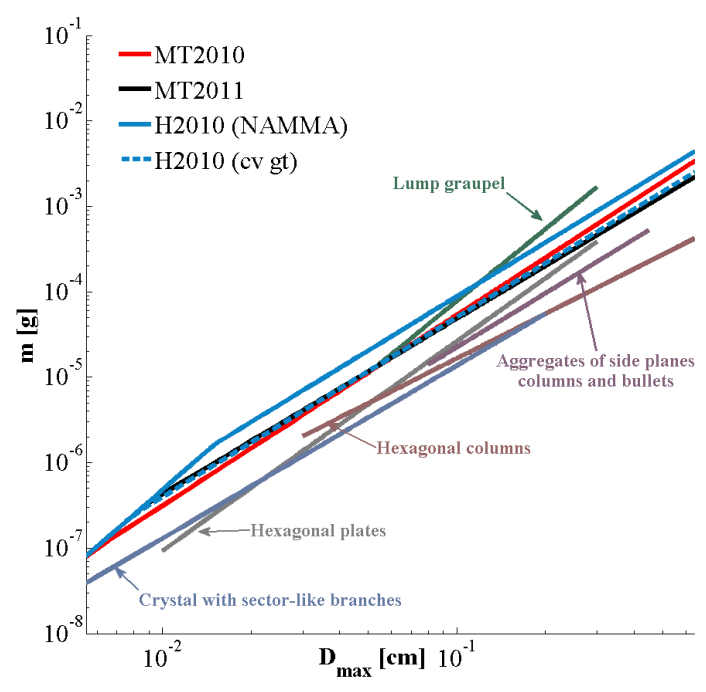

Figure 12. Mass of individual ice crystals in gram as a function of their $D_{\max }$. The red line represents mean values of $m(D)$ coefficients for MT2010 (Eq. 19). Likewise, the black dashed line represents $m(D)$ coefficients for MT2011 (Eq. 20). The blue line represents $m(D)$ coefficients taken from H10 for the NAMMA campaign and the dashed blue line also stems from $\mathrm{H} 10$, but for convectively generated. Finally, various $m(D)$ relationships are taken from M96, as there are the blue-grey line for crystals with sector-like branches, the grey line for hexagonal plates, the brown-grey line for hexagonal columns, the purple-grey line for aggregates of side planes columns and bullets, and the green line for lump graupel.

clude on an uncertainty for $\alpha_{\sigma}$ and CWC of roughly $20 \%$. The concentration uncertainties associated to the shattering are nevertheless mainly impacting the smaller sizes, the uncertainty of $\alpha_{\sigma}$ and CWC is then considered significantly smaller.

PSD used in this study solely take into account hydrometeors of $D_{\max }$ larger than $50 \mu \mathrm{m}$, even though the $2 \mathrm{D}-\mathrm{S}$ starts recording particles at $10 \mu \mathrm{m}$. However, due to significant measurement uncertainties (shattering effects, out of focus particle sizes and related sampling volume) of the concentration of small particles of only a few pixels in size the composite PSD used and presented in this study do not take into account particle diameters below $50 \mu \mathrm{m}$. The impact on CWC of $10-50 \mu \mathrm{m}$ size particles (not taken into account in this study) was estimated, comparing CWC values calculated in parallel for PSD starting at $10 \mu \mathrm{m}$ and starting at $50 \mu \mathrm{m}$. These comparisons illustrate that for more than $95 \%$ of the overall data set, the small hydrometeors with diameters below $50 \mu \mathrm{m}$ would have increased CWC values presented in this study by less than $1 \%$. 
Table 6. Ratio of fitted $\alpha_{T}$ over retrieved $\alpha_{\sigma}$, and of $\operatorname{CWC}\left(\alpha_{T}, \beta_{T}\right)$ calculated from fitted $\alpha_{T}$ and $\beta_{T}$ over CWC $\left(\alpha_{\sigma}, \beta_{\sigma}\right)$ calculated with T-matrix retrieved $\alpha_{\sigma}$ and $\beta_{\sigma}$. In addition, differences between $\beta_{T}$ and $\beta_{\sigma}$ are shown. Expected values of ratios and differences are given in column E. first quartile, median, and third quartile are given in $1 / 4,1 / 2$, and $3 / 4$ columns.

\begin{tabular}{lrrrr}
\hline & $\mathrm{E}$ & $1 / 4$ & $1 / 2$ & $3 / 4$ \\
\hline MT2010: $\alpha_{T} / \alpha_{\sigma}$ & 1.12 & 0.77 & 0.98 & 1.23 \\
MT2010: $\beta_{T}-\beta_{\sigma}$ & -0.02 & -0.14 & -0.03 & +0.08 \\
MT2010: $\mathrm{CWC}\left(\alpha_{T}, \beta_{T}\right) / \mathrm{CWC}\left(\alpha_{\sigma}, \beta_{\sigma}\right)$ & 1.03 & 0.86 & 0.98 & 1.15 \\
MT2011: $\alpha_{T} / \alpha_{\sigma}$ & 1.35 & 0.61 & 1.01 & 1.60 \\
MT2011: $\beta_{T}-\beta_{\sigma}$ & +0.03 & -0.13 & +0.03 & +0.21 \\
MT2011: CWC $\left(\alpha_{T}, \beta_{T}\right) / \mathrm{CWC}\left(\alpha_{\sigma}, \beta_{\sigma}\right)$ & 0.94 & 0.70 & 0.90 & 1.09 \\
\hline
\end{tabular}

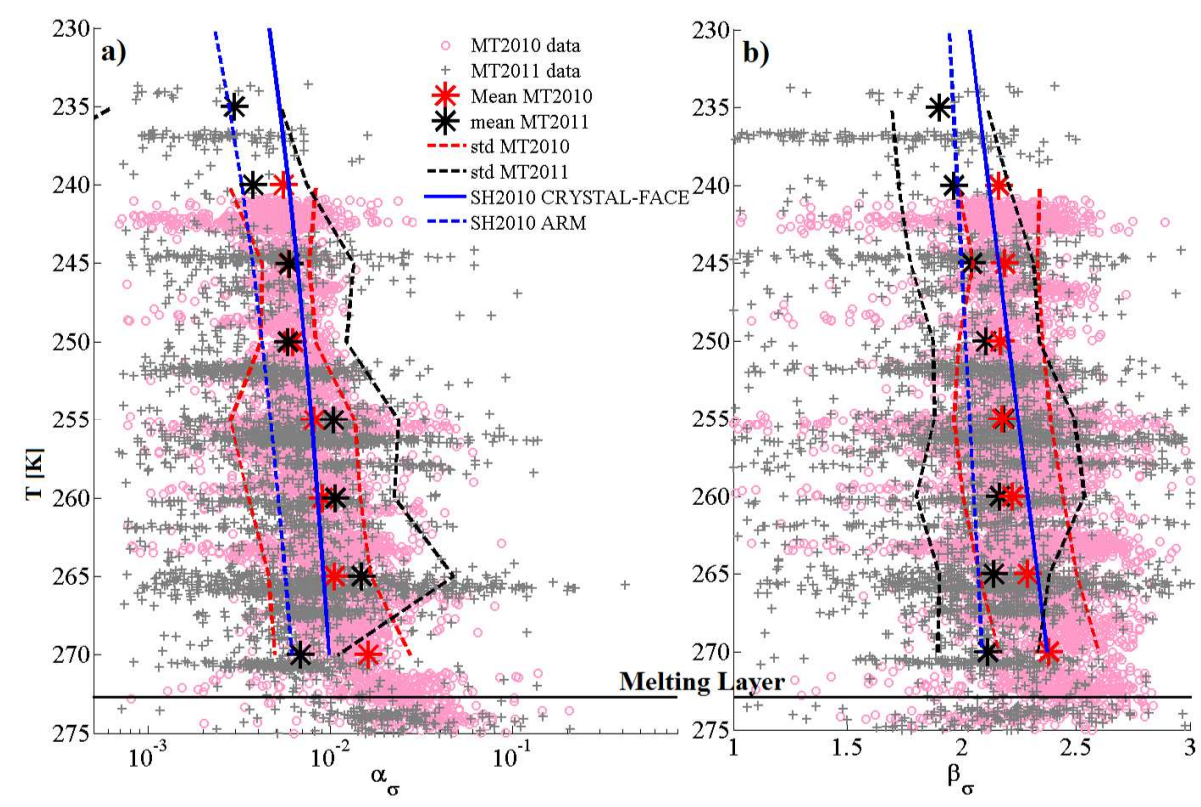

Figure 13. Vertical variability of $m(D)$ coefficients $\alpha_{\sigma}$ and $\beta_{\sigma}$. (a) $\alpha_{\sigma}$ versus the temperature in K. (b) $\beta_{\sigma}$ versus the temperature in K. Small symbols of pink circles show data points ( $5 \mathrm{~s}$ time step) of MT2010, whereas grey crosses show MT2011 data. Large symbols of red and black stars present mean values of $m(D)$ coefficients in $5 \mathrm{~K}$ temperature intervals for MT2010 and MT2011, respectively. Dashed red and black lines show standard deviations from the mean value for MT2010 and MT2011, respectively. Blue solid and dashed lines show vertical profiles of SH2010 obtained for CRYSTAL-FACE and for ARM campaigns, respectively.

\section{$4 m(D)$ relationship and impact on Z-CWC calculation}

\section{1 $m(D)$ variability}

In the previous section, it was demonstrated how $\beta_{\sigma}$ is derived from $S(D)$ power laws that are fitted separately for 2D-S and PIP image data with final calculation of one single exponent $\sigma$, yielding then $\beta_{\sigma}$ based on the theoretical work presented in Sect. 3.1. Then $\alpha_{\sigma}$ is constrained by reflectivities of RASTA, including subsequent calculation of CWC.

The two $m(D)$ coefficients $\left(\alpha_{\sigma}, \beta_{\sigma}\right)$ appear to be strongly correlated with each other, with a correlation coefficient (cc) that equals 0.81 for MT2010 (Fig. 11a) and 0.92 for MT2011 (Fig. 11b). This result was observed and discussed in H10. In H10, $m(D)$ coefficients were found by minimizing the differences between CWC estimated from particle imagery and measured bulk CWC. This was performed flight-by-flight for different airborne campaigns. Their data set was divided into two types of cirrus: convective cirrus and stratiform cirrus. H10 obtained trends for each type of cirrus by fitting the mean of the prefactor (here $\alpha$ ) as a function of the exponent (here $\beta$ ). In Fig. 11, the power law fit obtained for convective cirrus by $\mathrm{H} 10$ is added as a black line. We note in the semi$\log$ representations of Fig. 11, that the slope derived by $\mathrm{H} 10$ is exceeding the slopes calculated for MT2010 and MT2011, respectively. This may be explained by the fact that $\beta$ coefficients in H10 were calculated differently as compared to this study. However, both studies show that $\alpha$ (hereafter $\alpha_{\beta}$ ) can be fitted as an exponential function of $\beta$ (Eqs. 15 and 16 for 


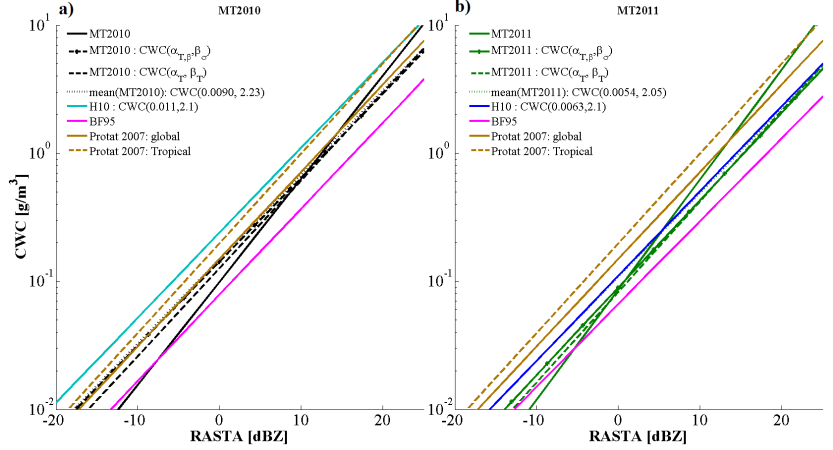

Figure 14. Z-CWC-fitted relationships between calculated CWC and measured radar reflectivities for MT2010 and MT2011 data sets. $Z$ is given in $\mathrm{dBZ}$ on the $x$ axis and CWC in $\mathrm{g} \mathrm{m}^{-3}$ on the $y$ axis. (a) Power law fits for MT2010. (b) Power law fits for MT2011.

MT2010 and MT2011, respectively).

$\operatorname{MT2010}: \alpha_{\beta}=7.10^{-5} \cdot e^{2.11 \cdot \beta_{\sigma}}$
MT2011: $\alpha_{\beta}=2.10^{-5} \cdot e^{2.65 \cdot \beta_{\sigma}}$

Furthermore, Fig. 11 reveals that temperature has an impact on the relationship between $\alpha_{\sigma}$ and $\beta_{\sigma}$, which was not discussed in H10. In particular, for a given exponent $\beta_{\sigma}$, the prefactor $\alpha_{\sigma}$ increases with temperature. Equations (17) and (18) take into account the temperature dependency of the $\alpha-\beta$ relation, where the temperature is given in $\mathrm{K}$ and the resulting prefactor is denoted $\alpha_{\beta, T}$.

MT2010: $\alpha_{\beta, T}=7.10^{-5} \cdot e^{2.11 \cdot \beta_{\sigma}}$

$\cdot\left(0.05888 \cdot e^{0.01071 \cdot T}+6.4 .10^{-17} \cdot e^{0.1331 \cdot T}\right)$,

MT2011: $\alpha_{\beta, T}=2.10^{-5} \cdot e^{2.65 \cdot \beta_{\sigma}}$

$\cdot 0.011834 \cdot e^{0.01535 \cdot T}$.

Table 5 shows ratios of $\alpha_{\beta}$ and $\alpha_{\beta, T}$ (calculated according to Eqs. $15,16,17$, and 18 ) over $\alpha_{\sigma}$ (constrained by $\mathbf{T}$-matrix simulations). Average and median values of these ratios are particularly close to 1 . The first and third quartiles illustrate the narrowing around the median ratio when parameterizing the $\alpha$ as a function of $\beta$ and the temperature for the two campaigns.

For the two MT campaigns the following mean coefficients of $m(D)$ were deduced:

$$
\begin{aligned}
& \text { MT2010: } m\left(D_{\max }\right)=0.0090 \cdot D_{\max }^{2.23} \\
& \text { MT2011: } m\left(D_{\max }\right)=0.0054 \cdot D_{\max }^{2.05} .
\end{aligned}
$$

In Fig. 12 these relationships are compared against $m(D)$ deduced in H10 on the hand for the NAMMA (NASA African Monsoon Multidisciplinary Analyses; Zipser et al. 2009) campaign and on the other hand for clouds which were convectively generated (hereafter cv-gt) during CRYSTALFACE (Cirrus Regional Study of Tropical Anvils and Cirrus Layers-Florida Area Cirrus Experiment; (Jensen et al.,
2004) and TC4 (Tropical Composition, Cloud and Climate Coupling ; (Toon et al., 2010; Heymsfield et al., 2010b). NAMMA was performed above the African continent. CRYSTAL-FACE took place in the southern part of Florida, whereas TC4 includes convective systems close to the InterTropical Convergence Zone (ITCZ) and other strong convection developed along the coast of Costa Rica. H10 fixed $m(D)$ coefficients for NAMMA such that $\alpha=0.011$ and $\beta=2.1$ and for cv-gt (CRYSTAL-FACE+TC4) $\alpha=0.0063$ and $\beta=2.1$. Furthermore, some $m(D)$ findings from M96 are also included in the figure. $m(D)$ relations of MT2011 and $\mathrm{H} 10$ for clouds convectively generated are very similar. The mean $m(D)$ derived for MT2010 yields crystal masses that are a factor of 2 smaller than those given by $\mathrm{H} 10$ for NAMMA. Still, mean $m(D)$ derived for MT2010, MT2011 and $\mathrm{H} 10(\mathrm{cv}-\mathrm{gt})$ reveal higher masses than those given by M96 (for different crystal species) with the exception for the lump graupel. The fact that H10 (NAMMA) found largest mass for ice hydrometeors below $1 \mathrm{~mm}$ in size may suppose that ice crystals were more rimed particles in the vicinity of the convective part of MCS (NAMMA campaign) as compared to their stratiform part (MT2010).

Figure 13 presents trends of $m(D)$ coefficients $\alpha_{\sigma}$ and $\beta_{\sigma}$ with cloud altitude in terms of temperature. The variability of $m(D)$ coefficient at a given temperature is important. Average $m(D)$ coefficients (large stars in Fig. 13) were calculated for temperature intervals of $5 \mathrm{~K}$ (in Fig. 13 large stars represent median values for $5 \mathrm{~K}$ temperature intervals). The calculated profiles for MT2011data include solely flights 45 and 46 with a well developed stratiform region of an extended convective system. Mean values of $\alpha_{\sigma}$ and $\beta_{\sigma}$ are not calculated beyond $272.5 \mathrm{~K}$ temperature level, since the T-matrix retrieval method does not take into account the liquid water at the surface of melting ice crystals. This should have an effect of increased reflectivity of ice crystals, leading to an underestimation of $m(D)$ coefficients. On average, mean $\beta_{\sigma}$ coefficients (Fig. 13a) are larger for MT2010 than for MT2011, whereas mean $\alpha_{\sigma}$ coefficients (Fig. 13b) are more similar and in the same order between the level $260-245 \mathrm{~K}$. The mean profiles show a decrease of mean $\alpha_{\sigma}$ and $\beta_{\sigma}$ coefficients with decreasing temperature described by Eqs. (21) and (22):

MT2010: $\left\{\begin{array}{l}\alpha_{T}=0.0020 \cdot e^{0.0037 \cdot T}+5.10^{-17} \cdot e^{0.1213 \cdot T} \\ \beta_{T}=7.13 \cdot e^{-0.0053 \cdot T}+5.4 .10^{-7} \cdot e^{0.0435 \cdot T}\end{array}\right.$

MT2011: $\left\{\begin{array}{l}\alpha_{T}=1.98 .10^{-6} \cdot e^{0.0310 \cdot T} \\ \beta_{T}=1.81 \cdot e^{-0.000755 \cdot T}-1.027 .10^{7} \cdot e^{-0.07454 \cdot T}\end{array}\right.$

In addition, $\alpha$ and $\beta$ profiles given by $\mathrm{SH} 2010$ for CRYSTAL-FACE and ARM (Atmospheric Radiation Measurement) campaigns are added to Fig. 13. This latter data set includes midlatitude cirrus clouds generated from large 

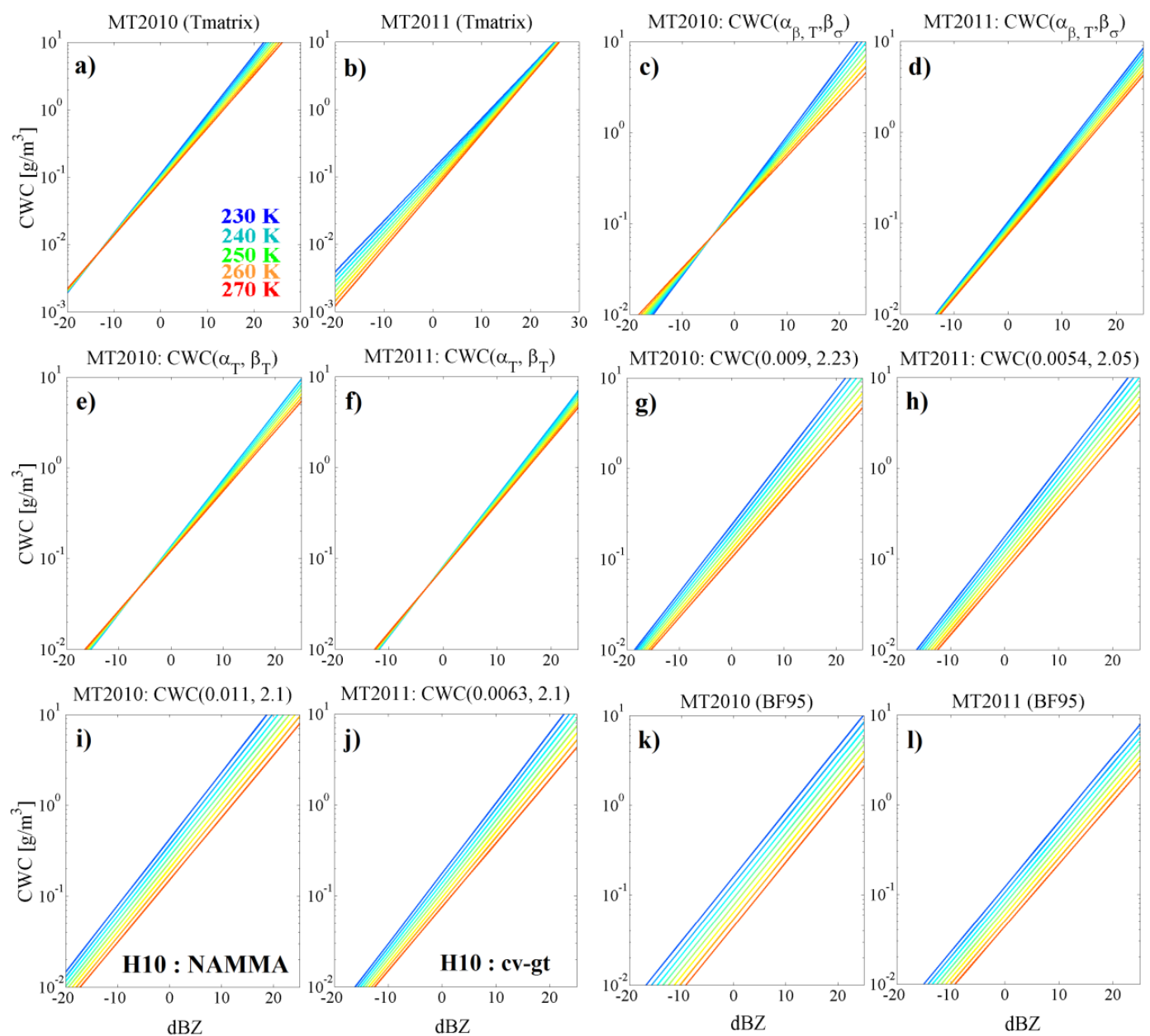

Figure 15. Z-CWC-T-fitted relationships between calculated CWC and measured radar reflectivities and temperatures for MT2010 and MT2011 data sets. Z is given in $\mathrm{dBZ}$ on the $x$ axis and CWC in $\mathrm{g} \mathrm{m}^{-3}$ on the $y$ axis. (a) CWC are calculated from $\alpha_{\sigma}$ and $\beta_{\sigma}$ for MT2010 data set. (b) as for (a) but for MT2011 (c) CWC are calculated using $\alpha_{\beta, T}$ and $\beta_{\sigma}$ for MT2010 data set. (d) as for (c) but for MT2011. (e) CWC are calculated as a function of $\alpha_{T}$ and $\beta_{T}$ for MT2010 (Eq. 21). (f) as for (e) but for MT2011 (Eq. 22). (g) CWC are calculated from average coefficient of MT2010 (Eq. 19). (h) as for (g) but for MT2011 (Eq. 20). (i) CWC are calculated using H10 $m(D)$ coefficients of NAMMA for MT2010. (j) CWC are calculated using H10 $m(D)$ coefficients of clouds convectively generated for MT2011. (k) CWC are calculated using the BF95 parameterization for MT2010 data set. (l) as for (k) but for MT2011.

scale uplift above the North American continent. Globally, $\beta_{\sigma}$ of MT2010 are similar to $\beta$ of CRYSTAL-FACE, and $\beta_{\sigma}$ of MT2011 are similar to $\beta$ of ARM given in SH2010.

Table 6 shows ratios of $\alpha_{T}$ over $\alpha_{\sigma}$ and $\operatorname{CWC}\left(\alpha_{T}, \beta_{T}\right)$ over $\operatorname{CWC}\left(\alpha_{\sigma}, \beta_{\sigma}\right)$, as well as differences between $\beta_{T}$ and $\beta_{\sigma}$. In general, $\alpha_{\sigma}$ for MT 2010 and MT2011 are overestimated by the fitted $\alpha_{T}$, whereas $\beta_{\sigma}$ is underestimated for MT2010 and overestimated for MT2011 by the fitted $\beta_{T}$. Finally, the resulting CWC calculations lead to average ratios of $\operatorname{CWC}\left(\alpha_{T}, \beta_{T}\right) / \operatorname{CWC}\left(\alpha_{\sigma}, \beta_{\sigma}\right) \approx 1.03$ (median value $\approx 1.01$ ) for MT2010 and $\operatorname{CWC}\left(\alpha_{T}, \beta_{T}\right) / \operatorname{CWC}\left(\alpha_{\sigma}, \beta_{\sigma}\right) \approx 0.94$ (median value $\approx 0.90$ ) for MT2011.

\section{2 $m(D)$ impact on $Z$-CWC and Z-CWC-T}

In the past, numerous studies were dedicated to relating CWC to radar reflectivity (Liu and Illingworth, 2000; Hogan et al., 2006; Protat et al., 2007). These studies illustrate that CWC can be estimated from the radar reflectivity at 94 or $35 \mathrm{G} \mathrm{Hz}$ using solely $Z-C W C$ relationships, but also when adding a temperature dependency $(Z-C W C-T$ relationship). In the following, $\operatorname{CWC}(\alpha, \beta)$ has been calculated for MT2010 and MT2011 data sets according to seven different methods: (1) T-matrix $\left(\mathrm{CWC}\left(\alpha_{\sigma}, \beta_{\sigma}\right)\right)$, (2) equations 17-18 (CWC $\left.\left(\alpha_{\beta, T}, \beta_{\sigma}\right)\right)$, (3) Eqs. (21-22) $\left(\mathrm{CWC}\left(\alpha_{T}, \beta_{T}\right)\right)$, (4) mean coefficients of Eqs. (19-20) $(\mathrm{CWC}(\alpha=0.0090$, $\beta=2.23$ for MT2010) and $\operatorname{CWC}(\alpha=0.0054, \beta=2.05$ for MT2010)), (5) BF95 parameterization, (6) and (7) from H10 
Table 7. Fitted $Z-C W C$ and $Z-C W C-T$ relationships according to $\mathrm{CWC}(\alpha, \beta)$ calculations with different methods for MT2010 and MT2011 data sets.

\begin{tabular}{lll}
\hline & $\mathrm{CWC}(\mathrm{Z})$ & $\mathrm{CWC}(\mathrm{Z}, \mathrm{T})$ \\
\hline T-matrix(MT2010) & $\mathrm{CWC}=0.0981 * Z^{0.805}$ & $\mathrm{CWC}=0.7183^{*} e^{-0.0078913 * T} * \mathrm{Z}^{(-0.002549 * T+1.4813)}$ \\
T-matrix (MT2011) & $\mathrm{CWC}=0.0869 * Z^{0.775}$ & $\mathrm{CWC}=18.4392^{*} e^{-0.02115 * T} * \mathrm{Z}^{(0.002659 * T+0.13467)}$ \\
MT2010(Eq. 17) & $\mathrm{CWC}=0.1421 * Z^{0.655}$ & $\mathrm{CWC}=0.44974 * e^{-0.004527 * T} * \mathrm{Z}^{(-0.0044794 * T+1.8224)}$ \\
MT2011(Eq. 18) & $\mathrm{CWC}=0.0893 * Z^{0.682}$ & $\mathrm{CWC}=0.93632 * e^{-0.0093472 * T} \mathrm{Z}^{(-0.0017635 T+1.1748)}$ \\
Mean(MT2010)(Eq. 19) & $\mathrm{CWC}=0.1490^{*} Z^{0.659}$ & $\mathrm{CWC}=62.9368^{*} e^{-0.023757 * T} * \mathrm{Z}^{(-0.002388 * T+1.3059)}$ \\
Mean(MT2011)(Eq. 20) & $\mathrm{CWC}=0.1084 * Z^{0.656}$ & $\mathrm{CWC}=65.3563 * e^{-0.025176 * T} * \mathrm{Z}^{(-0.0019304 * T+1.2195)}$ \\
MT2010(Eq. 21) & $\mathrm{CWC}=0.1261 * Z^{0.686}$ & $\mathrm{CWC}=0.3365^{*} e^{-0.0037815 * T} * \mathrm{Z}^{(-0.0026268 * T+1.3679)}$ \\
MT2011(Eq. 22) & $\mathrm{CWC}=0.0826 * Z^{0.708}$ & $\mathrm{CWC}=0.12055^{*} e^{-0.0016174 * T} * \mathrm{Z}^{(-0.0021477 * T+1.2853)}$ \\
H10(NAMMA) & $\mathrm{CWC}=0.2397 * Z^{0.664}$ & $\mathrm{CWC}=446.6519 * e^{-0.029602 * T} * \mathrm{Z}^{(-0.0012781 * T+1.0319)}$ \\
H10(cv-gt) & $\mathrm{CWC}=0.1101 * Z^{0.662}$ & $\mathrm{CWC}=52.153 * e^{-0.024225 * T} * \mathrm{Z}^{(-0.0020589 * T+1.2569)}$ \\
BF95 (MT2010) & $\mathrm{CWC}=0.0797 * Z^{0.668}$ & $\mathrm{CWC}=856.8913 * e^{-0.036509 * T} * \mathrm{Z}^{(-0.0001986 * T+0.76656)}$ \\
BF95 (MT2011) & $\mathrm{CWC}=0.0694 * Z^{0.635}$ & $\mathrm{CWC}=112.1674 * e^{-0.02908 * T} * \mathrm{Z}^{(-0.00076668 * T+0.90401)}$ \\
\hline
\end{tabular}
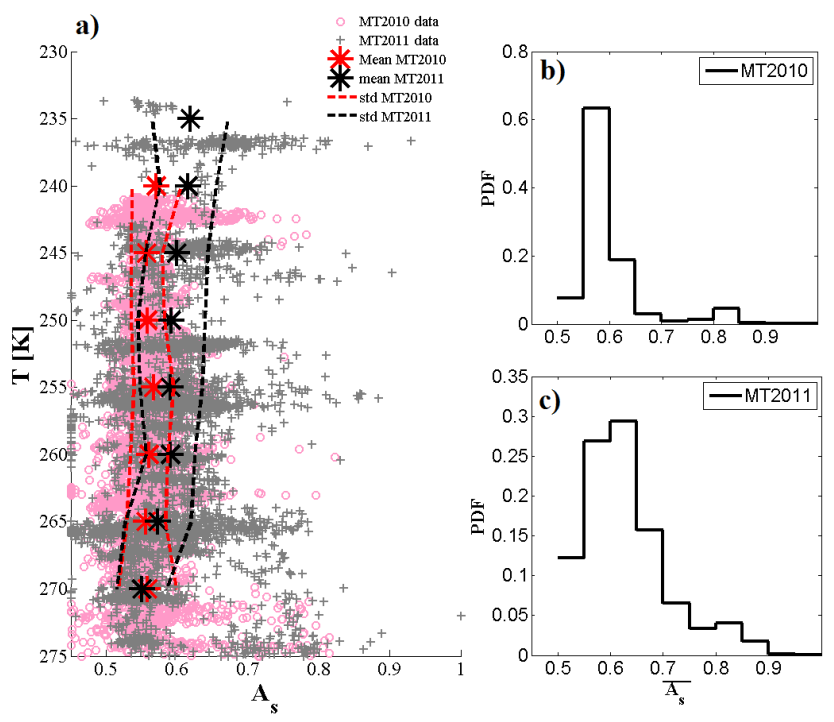

Figure 16. (a) Vertical profiles of the average aspect ratio $\overline{\mathrm{As}}$ as a function of temperature. Small symbols of pink circles show data points (5 s time step) of MT2010, whereas grey crosses show MT2011 data. Large symbols of red and black stars present mean values of $\overline{\mathrm{As}}$ in $5 \mathrm{~K}$ temperature intervals for MT2010 and MT2011, respectively. Dashed red and black lines show standard deviations for MT2010 and MT2011, respectively, from the average value. (b) Probability distribution functions of $\overline{\mathrm{As}}$ for MT2010. (c) Probability distribution functions of $\overline{\mathrm{As}}$ for MT2011.

for NAMMA and cv-gt parameterizations, respectively. In order to use the BF95- $m(D)$ relationship, PSD were calculated for both MT campaigns such that the particle diameter is $D=(L x+L y) / 2$. H10 (NAMMA) parameterization is used solely for the MT2010 PSD data, whereas H10 (cvgt) parameterization is used for the MT2011 PSD data. Table 7 gives an overview of $Z$-CWC and $Z-C W C-T$-fitted relationships between different $\mathrm{CWC}(\alpha \beta)$ calculated with above methods and measured radar reflectivities (RASTA). The fitted Z-CWC relations are presented in Fig. 14, whereas fitted $Z$-CWC- $T$ relations are presented in Fig. 15, with $Z$ given in $\mathrm{mm}^{6} \mathrm{~m}^{-3}$, CWC in $\mathrm{g} \mathrm{m}^{-3}$, and $T$ in K. In Figs. 14 and $15, Z$ is expressed in dBZ for convenience. Two further relationships given by Protat et al. (2007), hereafter denoted P2007 are added in Fig 14. Relationships given by P2007 are based on cloud in situ observations using a tropical data set (Eq. 23a) and from a global data set (Eq. 23b) which includes also mid-latitude and tropical clouds. Note that the BF95- $m(D)$ relationship has been assumed for all clouds in P2007 calculations.

$\mathrm{CWC}(Z)=0.149 Z^{0.681}$ Global P2007
$\operatorname{CWC}(Z)=0.198 Z^{0.701}$ Tropics P2007

Applying P2007 parameterizations for calculating CWC results in significantly larger CWC values, as compared to estimated CWC of this study for the Megha-Tropiques data set, which is particularly true for small reflectivities and most pronounced for MT2011 oceanic convection. This might be due to the fact that the in situ database used in P2007 encompasses a much larger variety of ice clouds, including low CWC cirrus clouds.

For MT2010, largest CWC are found when CWC are calculated with the H10 parameterization for the NAMMA data. BF95 parameterization calculates relatively low CWC values for all reflectivities which is also the case for CWC calculated with the T-matrix method for reflectivities below $0 \mathrm{dBZ}$. The other parameterizations from this study and the P2007 parameterization for the global datal set are similar and also close to T-matrix calculated CWC in the range 5 to $15 \mathrm{dBZ}$.

For MT2011, lowest CWC are calculated again with the BF95 parameterization. CWC calculations with H10 parameterization for convectively generated clouds and most of the parameterizations from this study are rather similar. 
In general, for both campaigns CWC increases more significantly with the reflectivity when calculated with the T-matrix method, as compared to CWC calculations from most $m(D)$ parameterizations (this study, H10, BF95).

In principal, $Z-C W C-T$ relationships allow improving the calculation of more realistic CWC as compared to simpler $Z-C W C$ relationships. In Table 8, for the two subsets of fitted relationships $(\mathrm{CWC}(Z)$ and $\mathrm{CWC}(Z, T))$, correlation coefficients (cc) are calculated between $\mathrm{CWC}(\alpha, \beta)$ and $\mathrm{CWC}(Z)$ or $\mathrm{CWC}(Z, T)$-fitted parameterizations, respectively. In addition, an error calculation (Eq. 24) is performed with $\operatorname{error}_{Z}$ and error $_{Z, T}$ defined as follows:

$\operatorname{error}_{Z}=100 \cdot \frac{|\mathrm{CWC}(Z)-\mathrm{CWC}(\alpha, \beta)|}{\mathrm{CWC}(\alpha, \beta)}$ or
$\operatorname{error}_{Z, T}=100 \cdot \frac{|\mathrm{CWC}(Z, T)-\mathrm{CWC}(\alpha, \beta)|}{\mathrm{CWC}(\alpha, \beta)}$.

Table 8 presents expected values $(E)$, median values, first quartiles, third quartiles, and the 90th percentiles for $\operatorname{error}_{Z, T}$ and error $_{Z}$. The lower part of this table presents the calculation of $\operatorname{error}_{Z, T}-$ error $_{Z}$ to demonstrate how CWC calculation from reflectivities is improved when the temperature is parameterized in the fitted relationships between $Z$ and $\operatorname{CWC}(\alpha, \beta)$.

Since the $m(D)$ coefficients within this study were constrained by the RASTA radar reflectivity, it is not surprising that $\operatorname{error}_{Z}, \operatorname{error}_{Z, T}$, and also the difference between these two errors ( $\operatorname{error}_{Z, T}-$ error $_{Z}$ ) are comparably small for CWC derived from $\mathbf{T}$-matrix method.

The fitted CWC-Z relationships for the other methods all produce significantly larger values for $\operatorname{error}_{Z}$ with maximum average error $_{Z}$ found for methods when $\mathrm{CWC}(\alpha, \beta)$ has been calculated from constant $m(D)$ coefficients. Furthermore, error $_{Z}$ for all methods is generally larger for MT2011 than for MT2010 data set. When fitting CWC-Z$\mathrm{T}$, this does not improve significantly correlations as compared to $\mathrm{CWC}-\mathrm{Z}$-fitted relations, neither for the time resolved $\mathbf{T}$-matrix method nor for $\operatorname{CWC}\left(\alpha_{T, \beta}, \beta_{\sigma}\right)$ (Eqs. 17 and 18) nor for $\mathrm{CWC}\left(\alpha_{T}, \beta_{T}\right)$ (Eqs. 21 and 22) methods, since therein the temperature has been implicitly taken into account for $\mathrm{CWC}(\alpha, \beta)$ calculation. In contrast, for the other methods applied to MT2010 and/or MT2011 data sets, as there are mean T-matrix, H10 (NAMMA), H10 (cv-gt), and BF95 the improvement is significant when the temperature is taken into account. Moreover the improvement is more efficient for these other methods for the MT2010 data set (error $_{Z}-$ error $_{Z, T}$ improvement $>10 \%$ ) as compared to the MT2011 data set ( error $_{Z}-$ error $_{Z, T}$ improvement $\leq 10 \%$ ).

Without considering here the original $\mathbf{T}$-matrix method to calculate CWC, it can be clearly seen from Table 8 that the average error $_{Z, T}$ ( error $_{Z}$, respectively) of all six remaining methods is smaller for MT2010 $\approx 38 \%$ (40\%) than for

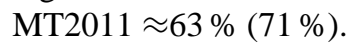

The differences in the performance of $m(D)$ parameterizations and respective impact on $\mathrm{CWC}(Z)$ and $\mathrm{CWC}(Z, T)$ relationships for MT2010 and MT2011 can be explained by the fact that the mean aspect ratio $\overline{\mathrm{As}}$ (Fig. 16) for MT2010 cloud particles shows rather constant values with altitude including small standard deviations (Fig. 16a) and even a very small standard deviation around the global average value (Fig. 16b). For MT2011 $\overline{\mathrm{As}}$ shows a broader distribution around the global average value and larger standard deviations with altitude (Fig. 16c and a). On average $\overline{\mathrm{As}}$ increases with altitude for MT2011, whereas $\overline{A s}$ for MT2010 remains more constant with altitude. Over $80 \%$ of the time $\overline{\mathrm{As}}$ for MT2010 is in the range [0.55;0.65] (Fig. 16b), whereas the broad $\overline{\mathrm{As}}$ spectrum for MT2011 tends to larger values (up to 0.8), as compared to MT2010, which means that MT2011 contains significant amounts of particles with a more spherical aspect ratio.

\section{Discussion and conclusion}

This study presents a method to calculate CWC from particle imagery and radar reflectivity at $94 \mathrm{GHz}$. Cloud particles are represented by oblate spheroids used for reflectivity calculations with the T-matrix method. The flattening of the spheroid is constrained by the average aspect ratio $\overline{\mathrm{As}}$ of the 2-D images recorded by the 2D-S and the PIP probes. An estimation of the $\beta$ exponent of the $m(D)$ relationship is derived from the measurements of the projected surface of 2-D images from 2D-S and PIP optical array probes. Then the prefactor $\alpha$ is calculated from simulated radar reflectivities matching the corresponding measured reflectivities at $94 \mathrm{GHz}$. The method was applied to two different data sets basically sampled in tropical stratiform anvils; the first one was sampled over the African continent (MT2010) and the second one was collected over the Indian Ocean (MT2011).

An important variability of the $m(D)$ coefficients has been found, especially for the MT2011 campaign. This result illustrates the main inconvenience to use a single $m(D)$ relationships in tropical clouds. In this study two different parameterizations were fitted to all constrained $m(D)$ coefficients (5s time resolution) for continental (MT2010) and oceanic (MT2011) data sets in tropical convection. The first parameterization allows us to calculate the $m(D)$ prefactor as a function of the temperature and the $m(D)$ exponent, showing that for a given exponent the prefactor increases with temperature for both campaigns. The second parameterization allows us to deduce both $m(D)$ coefficients (prefactor and exponent) as a function of the temperature. The latter result is in agreement with results shown in SH2010 for two different data set of convective clouds in tropical and midlatitude conditions.

Furthermore, this study demonstrates how Z-CWC and $Z-\mathrm{CWC}-T$ relationships are impacted by different methods used to retrieve CWC from the measured PSD during MT2010 and MT2011. In general, the use of a single temperature independent $m(D)$ relationship for all clouds is not appropriate, because it excludes the large natural variability 
Table 8. For seven different methods calculating $\mathrm{CWC}(\alpha, \beta)$, for MT2010 and MT2011 data sets, correlation coefficients (cc) between CWC $(\alpha, \beta)$ and fitted $\mathrm{CWC}(\mathrm{Z})$ and $\mathrm{CWC}(\mathrm{Z}, \mathrm{T})$, respectively, are shown in the left column. In addition, expected value E, 1st quartile, median, 3rd quartile and 90th percentile of $\operatorname{error}_{Z}$ and $\operatorname{error}_{Z, T}$ are presented. Also calculated below: error $Z, T$-error $Z$.

\begin{tabular}{|c|c|c|c|c|c|c|}
\hline \multicolumn{7}{|c|}{$\mathrm{CWC}(\mathrm{Z})$ versus $\mathrm{CWC}(\alpha, \beta)$; error $_{Z}: \mathrm{E}, 1 / 4,1 / 2,3 / 4,9 / 10$} \\
\hline & $\mathrm{cc}$ & $\mathrm{E}$ & $1 / 4$ & $1 / 2$ & $3 / 4$ & $9 / 10$ \\
\hline T-matrix(MT2010) & 0.96 & 24 & 7 & 15 & 28 & 52 \\
\hline T-matrix (MT2011) & 0.95 & 39 & 14 & 29 & 48 & 70 \\
\hline MT2010(Eq. 17) & 0.86 & 43 & 12 & 23 & 41 & 91 \\
\hline MT2011(Eq. 18) & 0.86 & 75 & 18 & 37 & 62 & 112 \\
\hline Mean(MT2010)(Eq. 19) & 0.85 & 49 & 15 & 29 & 48 & 103 \\
\hline Mean(MT2011)(Eq. 20) & 0.85 & 75 & 20 & 41 & 63 & 111 \\
\hline MT2010(Eq. 21) & 0.89 & 40 & 11 & 22 & 40 & 86 \\
\hline MT2011(Eq. 22) & 0.87 & 71 & 17 & 35 & 60 & 111 \\
\hline H10(NAMMA) & 0.84 & 51 & 15 & 30 & 49 & 105 \\
\hline $\mathrm{H} 10(\mathrm{cv}-\mathrm{gt})$ & 0.85 & 75 & 20 & 41 & 62 & 110 \\
\hline BF95(MT2010) & 0.83 & 54 & 16 & 32 & 53 & 113 \\
\hline BF95(MT2011) & 0.84 & 72 & 20 & 43 & 65 & 118 \\
\hline \multicolumn{7}{|c|}{$\mathrm{CWC}(\mathrm{Z}, \mathrm{T})$ versus $\mathrm{CWC}(\alpha, \beta) ;$ error $_{Z, T}: \mathrm{E}, 1 / 4,1 / 2,3 / 4,9 / 10$} \\
\hline & $\mathrm{cc}$ & $\mathrm{E}$ & $1 / 4$ & $1 / 2$ & $3 / 4$ & $9 / 10$ \\
\hline T-matrix(MT2010) & 0.90 & 22 & 7 & 14 & 25 & 47 \\
\hline T-matrix (MT2011) & 0.93 & 34 & 11 & 24 & 42 & 66 \\
\hline MT2010(Eq. 17) & 0.75 & 40 & 10 & 21 & 40 & 84 \\
\hline MT2011(Eq. 18) & 0.82 & 71 & 17 & 35 & 60 & 106 \\
\hline Mean(MT2010)(Eq. 19) & 0.81 & 39 & 10 & 22 & 40 & 83 \\
\hline Mean(MT2011)(Eq. 20) & 0.84 & 66 & 16 & 34 & 59 & 102 \\
\hline MT2010(Eq. 21) & 0.79 & 38 & 10 & 21 & 40 & 83 \\
\hline MT2011(Eq. 22) & 0.83 & 69 & 17 & 35 & 59 & 106 \\
\hline H10(NAMMA) & 0.81 & 38 & 10 & 21 & 39 & 79 \\
\hline $\mathrm{H} 10(\mathrm{cv}-\mathrm{gt})$ & 0.84 & 66 & 16 & 34 & 59 & 102 \\
\hline BF95(MT2010) & 0.81 & 38 & 10 & 21 & 39 & 76 \\
\hline BF95(MT2011) & 0.84 & 63 & 16 & 35 & 60 & 104 \\
\hline \multicolumn{7}{|l|}{$\operatorname{error}_{Z, T}$-error $_{Z}$} \\
\hline & & $\mathrm{E}$ & $1 / 4$ & $1 / 2$ & $3 / 4$ & $9 / 10$ \\
\hline T-matrix(MT2010) & & -2 & 0 & -1 & -3 & -5 \\
\hline T-matrix (MT2011) & & -5 & -3 & -5 & -6 & -4 \\
\hline MT2010(Eq. 17) & & -3 & -1 & -1 & 0 & -7 \\
\hline MT2011(Eq. 18) & & -4 & -1 & -2 & -1 & -6 \\
\hline mean(MT2010)(Eq. 19) & & -11 & -5 & -7 & -8 & -20 \\
\hline mean(MT2011)(Eq. 20) & & -9 & -4 & -8 & -3 & -10 \\
\hline MT2010(Eq. 21) & & -1 & -1 & -1 & 0 & -3 \\
\hline MT2011(Eq. 22) & & -2 & 0 & -1 & 0 & -5 \\
\hline H10(NAMMA) & & -13 & -5 & -9 & -11 & -26 \\
\hline $\mathrm{H} 10(\mathrm{cv}-\mathrm{gt})$ & & -9 & -4 & -7 & -3 & -9 \\
\hline BF95(MT2010) & & -16 & -6 & -11 & -14 & -36 \\
\hline BF95(MT2011) & & -10 & -4 & -9 & -5 & -14 \\
\hline
\end{tabular}

of $m(D)$ (as was also highlighted in (Protat and Williams, 2011).

For a series of different methods calculating $\operatorname{CWC}(\alpha, \beta)$ (T-matrix calculation and three parameterizations presented in this study and also taken from literature such as H10 and BF95) $Z-C W C$ and $Z-C W C-T$ relationships were derived between $\mathrm{CWC}(\alpha, \beta)$ and measured radar reflectivities for MT2010 and MT2011 data sets. Subsequently, CWC derived from Z-CWC and Z-CWC- $T$ relations were confronted with $\mathrm{CWC}(\alpha, \beta)$ originally calculated with the corresponding method.

The main result is shown with the improvement of decreasing error comparing Z-CWC-T ( $\left.\operatorname{error}_{Z, T}\right)$ with $Z$-CWC-fitted parameterizations $\left(\operatorname{error}_{Z}\right)$. For $\mathrm{CWC}(\alpha, \beta)$ 
methods using constant $m(D)$ coefficients (mean T-matrix, H10(NAMMA), H10(cv-gt), BF95), the error improvement (error ${ }_{Z, T}$-error $Z$ ) is significant, with an average of $-12 \%$ for MT2010 and $-9 \%$ for MT2011 data sets. In contrast, for $\mathrm{CWC}(\alpha, \beta)$ methods which take into account the variability of $m(D)$ coefficients $(\mathrm{CWC}(\alpha, \beta))$ as a function of temperature and more precisely as a function of 2-D images in original T-matrix) the error improvement on average is merely $-2 \%$ for MT2010 and $-4 \%$ for MT2011.

The fact that errors from $Z$-CWC- $T$ (or Z-CWC) relations are larger for MT2011 than for MT2010 data set can be explained by the strong variability of the mean aspect ratio $\overline{\mathrm{As}}$ of cloud particles observed during MT2011, whereas cloud particles for MT2010 show a narrower distribution of $\overline{\mathrm{As}}$, meaning that crystals aspect ratios are more uniform.
For MT2010 the parameterization of $m(D)$ coefficients with temperature (or altitude) seems to perform well in order to describe the $m(D)$ coefficients with on average $\operatorname{CWC}\left(\alpha_{T}, \beta_{T}\right) / \operatorname{CWC}\left(\alpha_{\sigma}, \beta_{\sigma}\right) \approx 1.03$ and $\operatorname{CWC}\left(\alpha_{\beta, T}, \beta_{\sigma}\right) / \mathrm{CWC}\left(\alpha_{\sigma}, \beta_{\sigma}\right) \approx 1.08$. Likewise, values for MT2011 are $\operatorname{CWC}\left(\alpha_{T}, \beta_{T}\right) / \mathrm{CWC}\left(\alpha_{\sigma}, \beta_{\sigma}\right) \approx 0.94$ and $\operatorname{CWC}\left(\alpha_{\beta, T}, \beta_{\sigma}\right) / \mathrm{CWC}\left(\alpha_{\sigma}, \beta_{\sigma}\right) \approx 0.99$ respectively. Despite a good consistency for the both campaigns, the significant variability for example of $\alpha_{T} / \alpha_{\sigma}, \beta_{T}-\beta_{\sigma}$, and $\operatorname{CWC}\left(\alpha_{T}, \beta_{T}\right) / \mathrm{CWC}\left(\alpha_{\sigma}, \beta_{\sigma}\right)$ has to be mentioned. The variability can be illustrated by 1 st and 3rd quartiles and is significantly higher for MT2011 than MT2010. This is due to the fact that the MT2011 data set covers more variable microphysical properties and/or processes of hydrometeors (significant contribution of water vapor diffusional growth) compared to MT2010 and even temperature corrected parameterizations would need to be further refined. An explanation could be that during MT2010 over the African continent the Falcon 20 research aircraft was flying in stratiform parts of the MCS, and despite the attempt to get close to the convective cells, they were too vigourous to be entered. Therefore the microphysical properties of ice crystals in MCS systems sampled during MT2010 were relatively similar. In contrast, during MT2011 the less vigorous oceanic convection may have been sampled partly during an earlier stage of convective activity and also crystal growth regimes may have been different, leading to an increased variety of microphysical properties. 


\section{Appendix A: Description of 3-D simulations}

Simulations of 3-D particle habits were performed with the overall objective to study the $S(D)$ and $m(D)$ relations including correlations between the two exponents of the power laws. The simulated shapes aim to be realistic or at least comparable to the variety of hydrometeors found in natural clouds. All crystal shapes considered have 3-D characteristics with known volume or mass and crystal orientations in the 3-D space are fairly distributed. Zikmunda and Vali (1972) show that rimed columns tends to be oriented in a way that the maximum length is perpendicular to the fall velocity and rimed plates are oriented such that the maximum surface is perpendicular to the motion. To quantify the uncertainty related to a possible predominant crystal orientation during sampling, the crystal mass is calculated on the one hand from a minimum $D_{\max }$ (which will be an underestimation with respect to its reel value) and on the other hand from a maximum $D_{\max }$ (Fig. A1). By modeling both types of projected $D_{\max }$ according to the crystal mass and doing this for all simulated shapes, we obtain the maximum uncertainty related to the projection of possibly oriented 3-D hydrometeors projected on a 2-D plane. On average it is found for all simulated habits that $\Delta \sigma= \pm 0.15$ and $\Delta \beta= \pm 0.31$.

\section{A1 Plates}

The schematic of a plate type crystal is presented in Fig. A2. The geometric parameters used are the thickness $H$ and the height $L$ between two opposed corners of the hexagon. The simulations distinguish four types of plates, in order to explore the influence of the ratio between $H$ and $L$ on the fitted power laws. Two simulations have a ratio of $H / L$ equal to 0.1 and 0.2 , whereas in the third simulation $H$ is equal to the square root of $L$ and in the fourth $H$ is constant and equal to four pixels. In all these simulations, $L$ is chosen randomly out of the interval from 20 to 200 pixels with 1000 thousands simulations of plates in each of the four cases.

\section{A2 Columns}

Figure A3, shows the principal schematic of a column with geometric parameters of height $H$ and thickness $L$ between two corners of the hexagon. As performed for the plates, four sets of simulations were performed for columns: two with a linear ratio between $H$ and $L$, with $H / L$ equal to 10 and 5, whereas in the third simulation $L$ is equal to the square root of $H$ and in the fourth $L$ is constant and equal to 16 pixels. $H$ was chosen out of the size range of $[10 ; 100]$ pixels with 1000 simulations for columns in each of the four cases.

\section{A3 Slender stellars and more solid stellars}

Two types of stellar crystals were simulated with a significant difference in the width of their branches (Fig. A4). We call these two types slender stellars (lower picture) and solid stellars (upper picture). For both types of stellars, four sets of 1000 simulations were performed. Two simulations have a ratio of $H / L$ equal to 0.1 and 0.2 , whereas in the third simulation $H$ is equal to the square root of $L$ and in the fourth simulation $H$ is constant and equal to four pixels.

\section{A4 Capped columns}

One type of capped columns was simulated and processed, where the column is capped by two plates. The schematic description of a capped column is shown in Fig. A5. $L_{1}$ is the height of the two plates (and large stellars) at the top of the column, $L_{2}\left(=2.5 L_{1}\right)$ is the thickness of the column, and $H\left(=L_{1}\right)$ is its height. For the two simulations $\mathrm{L}_{1}$ varied between 10 and 100 pixels and the width of the plates (or stellars) was set to four pixels. In total 1000 simulations of capped columns were performed.

\section{A5 Rosettes}

A rosette with six branches randomly oriented is shown in Fig. A6. To simplify the scheme of the bullets that constitute the rosette, the bullets are assimilated as hexagonal columns. All the bullets belonging to the same rosette have identical size parameters, where $H$ is the bullet's height, $L$ its thickness, and $N$ the maximum number of bullets building the rosette.

In total, eight series of simulations were performed, varying $N$ between three and six bullets. Two simulation series were performed with $N$ equal to 3, and where the bullets are described either by $L$ equal to the square root of $H$ or $L$ equal to 5 pixels. $H$ was chosen out of the size range of 5 to 50 pixels.

Two sets of simulations followed where $N$ is equal to 4 and where the bullets are described by $\mathrm{L}$ equal to the square root of $H$ or $L$ equal to 10 pixels. $H$ has been chosen out of the size range of 10 to 100 pixels.

One set of simulations was performed where $\mathrm{N}$ is equal to 5 and where the bullets are described by the ratio $L / H$ equal to 0.5 . $H$ has been chosen out of the size range of 10 to 100 pixels. 
Finally, three additional sets of simulations were performed where $N$ is equal to 6 and where the bullets are described either by $L$ equal to the square root of $H$ or by $L$ equal to 10 pixels or where the ratio $L / H$ equal to 0.25 . $H$ has been chosen out of the size range of 10 to 100 pixels. All series were studied with 1000 simulations of rosettes.

\section{A6 Aggregates of individual crystal shapes}

Furthermore, aggregates of the individual shapes presented above were also simulated. Without going into some details of crystal aggregation processes (Westbrook et al., 2004), here we solely study the phenomenon of 3-D ice crystal aggregates projected on a 2-D plane. The number of individual crystals $\left(N_{\text {agg }}\right)$ used to form an aggregate has been varied. Individual crystals are randomly oriented in the 3-D space, before they stick together forming the aggregate. An example of an aggregate of spheres is shown in Fig. A7. $N$ is the random number of spheres, ranging between 3 and 50, which are aggregated, and $D$ is the diameter of one sphere which is set constant and equals six pixels. In total 1000 simulations of aggregated spheres were performed. 
Table A1. List of symbols.

\begin{tabular}{|c|c|}
\hline 2D-S & 2-D stereographic optical array probe with a resolution of $10 \mu \mathrm{mbin}^{-1}$ \\
\hline 2D-C & 2-D cloud particle optical array probe with a resolution of $25 \mu \mathrm{m} \mathrm{bin}-1$ \\
\hline 2D-P & 2-D precipitation particle optical array probe with a resolution of $200 \mu \mathrm{m} \mathrm{bin}^{-1}$ \\
\hline$\alpha$ & Pre-factor of mass-diameter relationship in general \\
\hline$\alpha_{\sigma}$ & Pre-factor of mass-diameter relationship calculated from the $\mathbf{T}$-matrix method when $\beta$ is calculated from Eq. (5) \\
\hline$\alpha_{\beta}$ & Pre-factor of mass-diameter relationship calculated as a function of $\beta_{\sigma}(\mathrm{Eq} .15$ and 16) \\
\hline$\alpha_{T}$ & Pre-factor of mass-diameter relationship calculated as a function of the temperature (Eqs. 21 and 22) \\
\hline$\alpha_{\beta, T}$ & Pre-factor of mass-diameter relationship calculated as a function of the temperature and $\beta_{\sigma}$ (Eqs. 17 and 18) \\
\hline$\beta$ & Exponent of mass-diameter relationship in general \\
\hline$\beta_{T}$ & Exponent of mass-diameter relationship calculated calculated in function of the temperature (Eqs. 21 and 22) \\
\hline$\beta_{\sigma}$ & Exponent of mass-diameter relationship calculated from Eq. (5) \\
\hline $\mathrm{A}_{r}$ & Area ratio: projected surface divided by $\left(\pi / 4 * D_{\max }^{2}\right)$ \\
\hline As & Mean aspect ratio for a given $D_{\max }\left(=\right.$ width/ $\left.D_{\max }\right)$ \\
\hline As & Aspect ratio distribution \\
\hline$\overline{\mathrm{As}}$ & Mean aspect ratio of all valid 2-D images recorded during a $5 \mathrm{~s}$ time period \\
\hline BRAIN & Bayesian rain rate retrieval algorithm including neural network \\
\hline CPI & Cloud particle imager, SPEC, Inc. \\
\hline CWC & Condensed water content (in general) \\
\hline $\mathrm{CWC}_{\mathrm{B} \& \mathrm{~L}}$ & CWC deduced from the Baker and Lawson scheme \\
\hline $\operatorname{CWC}\left(\alpha_{\sigma}, \beta_{\sigma}\right)$ & CWC calculated with $\alpha_{\sigma}$ and $\beta_{\sigma}$ \\
\hline $\operatorname{CWC}\left(\alpha_{T}, \beta_{T}\right)$ & CWC calculated with $\alpha_{T}$ and $\beta_{T}$ \\
\hline $\operatorname{CWC}\left(\alpha_{\beta, T}, \beta_{\sigma}\right)$ & CWC calculated with $\alpha_{\beta, T}$ and $\beta_{\sigma}$ \\
\hline$D_{\max }$ & Maximum length of the 2-D images of the hydrometeors \\
\hline$\Delta D_{\max }$ & Bin resolution of the size distribution \\
\hline$D_{\mathbf{T}}$-matrix & Diameter of an oblate spheroid used by the $\mathbf{T}$-matrix method \\
\hline$\Delta \mathrm{CWC}_{\max }$ & Uncertainty of the retrieved CWC from RASTA reflectivity and 2-D imagery of OAP \\
\hline $\operatorname{error}_{Z}$ & Absolute error using Z-CWC power fit and the retrieved CWC \\
\hline $\operatorname{error}_{Z, T}$ & Absolute error using $Z$-CWC- $T$ power fit and the retrieved CWC \\
\hline$f_{\text {ice }}$ & Ice fraction used fort the calculation of the backscattering properties of the hydrometeors \\
\hline MADRAS & Microwave analysis \& detection of rain \& atmospheric systems \\
\hline$m(D)$ & Mass-diameter relationship \\
\hline MT2010 & Megha-Tropiques Falcon 20 measurement campaign (Niger, August 2010) \\
\hline MT2011 & Megha-Tropiques Falcon 20 measurement campaign (Gan, November-December 2011) \\
\hline$N_{2 \mathrm{D}-\mathrm{S}}$ & Number concentration of hydrometeors counted by the 2D-S \\
\hline$N_{\text {PIP }}$ & Number concentration of hydrometeors counted by the PIP \\
\hline$N$ & Number concentration of hydrometeors \\
\hline$N_{\mathrm{t}}$ & Total number concentration of hydrometeors \\
\hline OAP & Optical array probe \\
\hline $\mathrm{Pi}$ & Probability distribution function used to calculate the average aspect ratio \\
\hline PIP & Precipitation imaging probe \\
\hline PSD & Particle size distribution \\
\hline RASTA & French acronym for Radar Aéroporté et Sol de Télédétection des propriétés nuAgeuse \\
\hline$\rho_{\text {ice }}$ & Ice density: $0.917 \mathrm{~g} \mathrm{~cm}^{-3}$ \\
\hline$S(D)$ & Surface-diameter relationship or area-diameter relationship \\
\hline$\sigma$ & Exponent of surface-diameter relationship in general \\
\hline$\sigma_{2 \mathrm{D}-\mathrm{S}}$ & Exponent of surface-diameter relationship from the 2D-S 2-Dimages \\
\hline$\sigma_{\mathrm{PIP}}$ & Exponent of surface-diameter relationship from the PIP 2-D images \\
\hline $\mathrm{Sp}$ & Projected surface of a hydrometeor recorded by an OAP \\
\hline$T$ & Temperature in Kelvin \\
\hline$Q_{\text {back }}$ & Total backscattering coefficient as a function of $D_{\max }$ per bin \\
\hline$Z$ & RASTA reflectivity at $94 \mathrm{GHz}$ \\
\hline Z-CWC & Fitted power law between reflectivity and CWC \\
\hline$Z-C W C-T$ & Fitted power law between reflectivity and $\mathrm{CWC}$, adding a temperature dependency parameterization \\
\hline
\end{tabular}




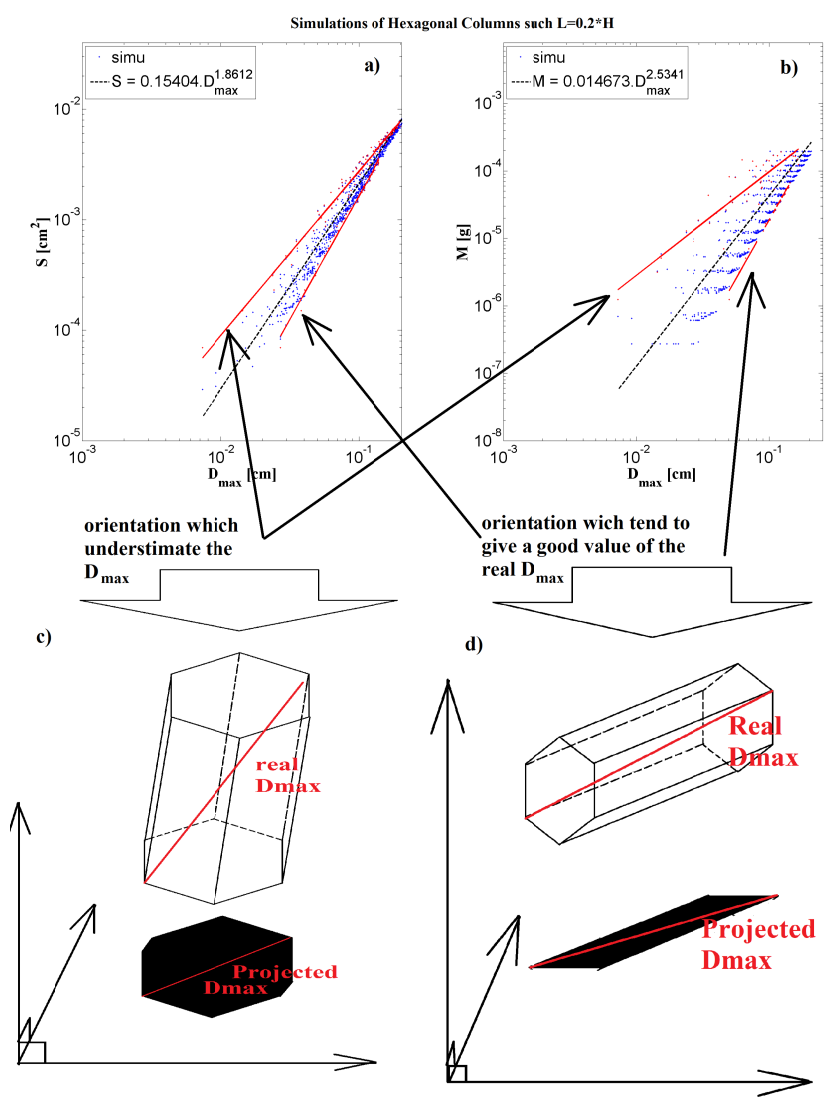

Figure A1. Exemplary results obtained for a 3-D simulation of columns characterized by length $=0.2 *$ height. (a) $S(D)$ plot: blue points are the simulated data for the column, red lines are power law fits enclosing most of the data points for all possible orientations. The dashed black line is the mean of the two power laws ( $=$ the mean between two red lines when the orientation underestimates $D_{\max }$ ) and when the orientation is close to the real $D_{\max }$ ). (b) $m(D)$ plot: same as for (a) but with the mass of the simulated columns which is now on the $y$ axis; (c) Schematic of a 3-D shape oriented in the 3-D space when its orientation gives an underestimated value of the real $D_{\max }$ of the ice crystals. (d) Schematic of a 3-D shape oriented in the 3-D space when its orientation gives a close value of the real $D_{\max }$ of the ice crystals.

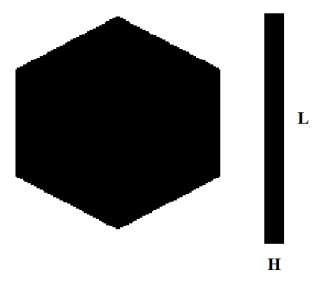

Figure A2. Schematic description of hydrometeors shapes for subsequent simulations of plates.

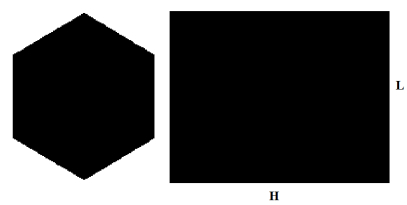

Figure A3. Schematic description of hydrometeors shapes for subsequent simulations of columns.
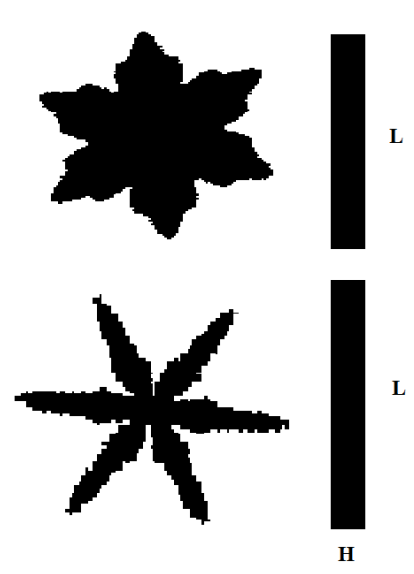

Figure A4. Schematic description of hydrometeors shapes for subsequent simulations of slender and solid stellars.

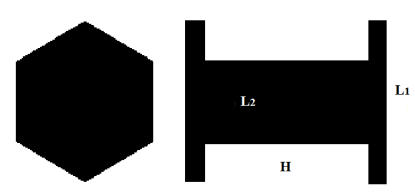

Figure A5. Schematic description of hydrometeors shapes for subsequent simulations of capped columns.

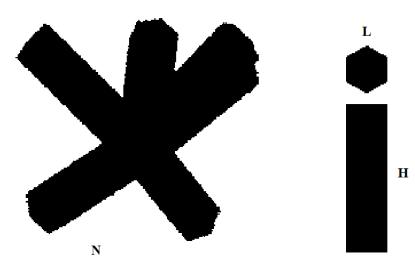

Figure A6. Schematic description of hydrometeors shapes for subsequent simulations of bullet rosettes.

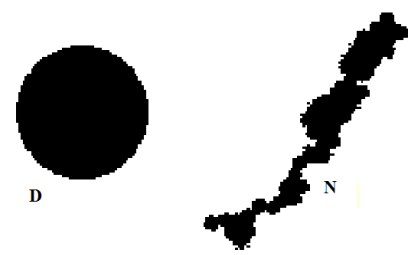

Figure A7. Schematic description of hydrometeors shapes for subsequent simulations of aggregates of spheres. 
Acknowledgements. The authors are particularly grateful to CNES for funding the aircraft measurement campaigns within the MeghaTropiques project. Furthermore, we would like to thank SAFIRE for operating the French Falcon 20 research aircraft during the two campaigns.

Edited by: T. Garrett

\section{References}

Bailey, M. and Hallett, J.: Growth Rates and Habits of Ice Crystals between $-20^{\circ}$ and $-70^{\circ} \mathrm{C}$, J. Atmos. Sci., 61, 514-544, doi:10.1175/1520-0469(2004)061<0514:GRAHOI>2.0.CO;2, 2004.

Bailey, M. P. and Hallett, J.: A Comprehensive Habit Diagram for Atmospheric Ice Crystals: Confirmation from the Laboratory, AIRS II, and Other Field Studies, J. Atmos. Sci., 66, 2888-2899, doi:10.1175/2009JAS2883.1, 2009.

Baker, B. and Lawson, R. P.: Improvement in Determination of Ice Water Content from Two-Dimensional Particle Imagery. Part I: Image-to-Mass Relationships, J. Appl. Meteorol. Clim., 45, 1282-1290, doi:10.1175/JAM2398.1, 2006.

Baumgardner, D. and Korolev, A.: Airspeed Corrections for Optical Array Probe Sample Volumes, J. Atmos. Ocean. Tech., 14, 1224-1229, doi:10.1175/15200426(1997)014<1224:ACFOAP>2.0.CO;2, 1997.

Brown, P. R. A. and Francis, P. N.: Improved Measurements of the Ice Water Content in Cirrus Using a Total-Water Probe, J. Atmos. Ocean. Tech., 12, 410-414, doi:10.1175/15200426(1995)012<0410:IMOTIW>2.0.CO;2, 1995.

Cetrone, J. and Houze, R. A.: Anvil clouds of tropical mesoscale convective systems in monsoon regions, Q. J. Roy. Meteor. Soc., 135, 305-317, doi:10.1002/qj.389, 2009.

Field, P. R., Wood, R., Brown, P. R. A., Kaye, P. H., Hirst, E., Greenaway, R., and Smith, J. A.: Ice Particle Interarrival Times Measured with a Fast FSSP, J. Atmos. Ocean. Tech., 20, 249-261, doi:10.1175/1520-0426(2003)020<0249:IPITMW>2.0.CO;2, 2003.

Field, P. R., Heymsfield, A. J., and Bansemer, A.: Shattering and Particle Interarrival Times Measured by Optical Array Probes in Ice Clouds, J. Atmos. Ocean. Tech., 23, 1357-1371, doi:10.1175/JTECH1922.1, 2006.

Frey, W., Borrmann, S., Kunkel, D., Weigel, R., de Reus, M., Schlager, H., Roiger, A., Voigt, C., Hoor, P., Curtius, J., Krämer, M., Schiller, C., Volk, C. M., Homan, C. D., Fierli, F., Di Donfrancesco, G., Ulanovsky, A., Ravegnani, F., Sitnikov, N. M., Viciani, S., D’Amato, F., Shur, G. N., Belyaev, G. V., Law, K. S., and Cairo, F.: In situ measurements of tropical cloud properties in the West African Monsoon: upper tropospheric ice clouds, Mesoscale Convective System outflow, and subvisual cirrus, Atmos. Chem. Phys., 11, 5569-5590, doi:10.5194/acp-11-55692011, 2011.

Heymsfield, A. J. and Parrish, J. L.: A Computational Technique for Increasing the Effective Sampling Volume of the PMS Two-Dimensional Particle Size Spectrometer, J. Appl. Meteorol., 17, 1566-1572, doi:10.1175/15200450(1978)017<1566:ACTFIT>2.0.CO;2, 1978.
Heymsfield, A. J. and Westbrook, C. D.: Advances in the Estimation of Ice Particle Fall Speeds Using Laboratory and Field Measurements, J. Atmos. Sci., 67, 2469-2482, doi:10.1175/2010JAS3379.1, 2010.

Heymsfield, A. J., Lewis, S., Bansemer, A., Iaquinta, J., Miloshevich, L. M., Kajikawa, M., Twohy, C., and Poellot, M. R.: A General Approach for Deriving the Properties of Cirrus and Stratiform Ice Cloud Particles, J. Atmos. Sci., 59, 3-29, doi:10.1175/1520-0469(2002)059<0003:AGAFDT>2.0.CO;2, 2002.

Heymsfield, A. J., Wang, Z., and Matrosov, S.: Improved Radar Ice Water Content Retrieval Algorithms Using Coincident Microphysical and Radar Measurements, J. Appl. Meteorol., 44, 13911412, doi:10.1175/JAM2282.1, 2005.

Heymsfield, A. J., Schmitt, C., Bansemer, A., and Twohy, C. H.: Improved Representation of Ice Particle Masses Based on Observations in Natural Clouds, J. Atmos. Sci., 67, 3303-3318, doi:10.1175/2010JAS3507.1, 2010a.

Heymsfield, G. M., Tian, L., Heymsfield, A. J., Li, L., and Guimond, S.: Characteristics of Deep Tropical and Subtropical Convection from Nadir-Viewing High-Altitude Airborne Doppler Radar, J. Atmos. Sci., 67, 285-308, doi:10.1175/2009JAS3132.1, 2010b.

Hogan, R. J., Mittermaier, M. P., and Illingworth, A. J.: The Retrieval of Ice Water Content from Radar Reflectivity Factor and Temperature and Its Use in Evaluating a Mesoscale Model, J. Appl. Meteorol. Clim., 45, 301-317, doi:10.1175/JAM2340.1, 2006.

Hogan, R. J., Tian, L., Brown, P. R. A., Westbrook, C. D., Heymsfield, A. J., and Eastment, J. D.: Radar Scattering from Ice Aggregates Using the Horizontally Aligned Oblate Spheroid Approximation, J. Appl. Meteorol. Clim., 51, 655-671, doi:10.1175/JAMC-D-11-074.1, 2011.

Houze, R. A.: Mesoscale convective systems, Rev. Geophys., 42, 1-43, doi:10.1029/2004RG000150, 2004.

Huffman, G. J., Adler, R. F., Bolvin, D. T., Gu, G., Nelkin, E. J., Bowman, K. P., Hong, Y., Stocker, E. F., and Wolff, D. B.: The TRMM Multisatellite Precipitation Analysis (TMPA): QuasiGlobal, Multiyear, Combined-Sensor Precipitation Estimates at Fine Scales, J. Hydrol., 8, 38-55, doi:10.1175/JHM560.1, 2007.

Jensen, E., Starr, D., and Toon, O. B.: Mission investigates tropical cirrus clouds, Eos Trans. AGU, 85, 45-50, doi:10.1029/2004EO050002, 2004.

Jensen, M. P. and Del Genio, A. D.: Radiative and Microphysical Characteristics of Deep Convective Systems in the Tropical Western Pacific, J. Appl. Meteorol., 42, 1234-1254, doi:10.1175/1520-0450(2003)042<1234:RAMCOD>2.0.CO;2, 2003.

Kobayashi, R.: Modeling and numerical simulations of dendritic crystal growth, Physica D, 63, 410-423, doi:10.1016/01672789(93)90120-P, 1993.

Liu, C.-L. and Illingworth, A. J.: Toward More Accurate Retrievals of Ice Water Content from Radar Measurements of Clouds, J. Appl. Meteorol., 39, 1130-1146, doi:10.1175/15200450(2000)039<1130:TMAROI>2.0.CO;2, 2000.

Locatelli, J. D. and Hobbs, P. V.: Fall speeds and masses of solid precipitation particles, J. Geophys. Res., 79, 2185-2197, doi:10.1029/JC079i015p02185, 1974. 
Maxwell Garnet, J. C.: Colours in Metal Glasses and in Metallic Films, Philos. T. Roy. Soc., 203, 385-420, doi:10.1098/rsta.1904.0024, 1904.

McFarquhar, G. M., Timlin, M. S., Rauber, R. M., Jewett, B. F., Grim, J. A., and Jorgensen, D. P.: Vertical Variability of Cloud Hydrometeors in the Stratiform Region of Mesoscale Convective Systems and Bow Echoes, Mon. Weather Rev., 135, 3405-3428, doi:10.1175/MWR3444.1, 2007.

Mishchenko, M. I., Travis, L. D., and Mackowski, D. W.: T-matrix computations of light scattering by nonspherical particles: A review, J. Quant. Spectrosc. Ra., 55, 535-575, doi:10.1016/00224073(96)00002-7, 1996.

Mitchell, D. L.: Use of Mass- and Area-Dimensional Power Laws for Determining Precipitation Particle Terminal Velocities, J. Atmos. Sci., 53, 1710-1723, doi:10.1175/15200469(1996)053<1710:UOMAAD>2.0.CO;2, 1996.

Mitchell, D. L., Zhang, R., and Pitter, R. L.: Mass-dimensional relationships for ice particles and the influence of riming on snowfall rates, J. Appl. Meteorol., 29, 153-163, doi:10.1175/15200450(1990)029<0153:MDRFIP>2.0.CO;2, 1990.

Nicholls, S., Leighton, J., and Barker, R.: A new fast response instrument for measuring total water content from aircraft, J. Atmos. Ocean. Tech., 7, 706-718, doi:10.1175/15200426(1990)007<0706:ANFRIF>2.0.CO;2, 1990.

Ogren, J. A., Heintzenberg, J., and Charlson, R. J.: In-situ sampling of clouds with a droplet to aerosol converter, Geophys. Res. Lett., 12, 121-124, doi:10.1029/GL012i003p00121, 1985.

Protat, A. and Williams, C. R.: The Accuracy of Radar Estimates of Ice Terminal Fall Speed from Vertically Pointing Doppler Radar Measurements, J. Appl. Meteorol. Climatol., 50, 21202138, doi:10.1175/JAMC-D-10-05031.1, 2011.

Protat, A., Delanoë, J., Bouniol, D., Heymsfield, A. J., Bansemer, A., and Brown, P.: Evaluation of ice water content retrievals from cloud radar reflectivity and temperature using a large airborne in situ microphysical database, J. Appl. Meteorol. Clim., 46, 557-572, doi:10.1175/JAM2488.1, 2007.

Protat, A., Bouniol, D., Delnoë, J., May, P. T., Plana-Fattori, A., Hasson, A., O'Connor, E., Görsdorf, U., and Heymsfield, A. J.: Assessment of cloudsat reflectivity measurements and ice cloud properties using ground-based and airborne cloud radar observations, J. Atmos. Ocean. Tech., 26, 1717-1741, doi:10.1175/2009JTECHA1246.1, 2009.
Schmitt, C. G. and Heymsfield, A. J.: The dimensional characteristics of ice crystal aggregates from fractal geometry, J. Atmos. Sci., 67, 1605-1616, doi:10.1175/2009JAS3187.1, 2010.

Spencer, R. W., Goodman, H. M., and Hood, R. E.: Precipitation retrieval over land and ocean with the SSM/I: identification and characteristics of the scattering signal, J. Atmos. Ocean. Tech., 6, 254-273, doi:10.1175/15200426(1989)006<0254:PROLAO>2.0.CO;2, 1989.

Tang, D. and Marangoni, A. G.: 3D fractal dimension of fat crystal networks, Chem. Phys. Lett., 433, 248-252, doi:10.1016/j.cplett.2006.11.057, 2006.

Toon, O. B., Star, D. O., Jensen, E. J., Newman, P. A., Platnick, S., Schoeberl, M. R., Wennberg, P. O., Wofsy, S. C., Kurylo, M. J., Maring, H., Jucks, K. W., Craig, M. S., Vasques, M. F., Pfister, L., Rosenlof, K. H., Selkirk, H. B., Colarco, P. R., Kawa, S. R., Mace, G. G., Minnis, P., and Pickering, K. E.: Planning, implementation, and first results of the Tropical Composition, Cloud and Climate Coupling Experiment (TC4), J. Geophys. Res. Atmos., 115, n/a-n/a, doi:10.1029/2009JD013073, 2010.

Viltard, N., Burlaud, C., and Kummerow, C. D.: Rain Retrieval from TMI Brightness Temperature Measurements Using a TRMM PR-Based Database, J. Appl. Meteorol. Climatol., 45, 455-466, doi:10.1175/JAM2346.1, 2006.

Westbrook, C. D., Ball, R. C., Field, P. R., and Heymsfield, A. J.: Theory of growth by differential sedimentation, with application to snowflake formation, Phys. Rev. E., 70, 021403, doi:10.1103/PhysRevE.70.021403, 2004.

Zikmunda, J. and Vali, G.: Fall Patterns and Fall Velocities of Rimed Ice Crystals, J. Atmos. Sci., 29, 1334-1347, doi:10.1175/15200469(1972)029<1334:FPAFVO>2.0.CO;2, 1972.

Zipser, E. J., Twohy, C. H., Tsay, S.-C., Hsu, N. C., Heymsfield, G. M., Thornhill, K. L., Taneli, S., Robert, R., Krishnamurti, T. N., Ji, Q., Jenkins, G., Ismail, S., Ferrare, R., Chen, G., Browell, E. V., Anderson, B., Hood, R., Goodman, H. M., Heymsfield, A. J., Halverson, J., Dunion, J. P., Douglas, M., and Cifelli, R.: The Saharan Air Layer and the Fate of African Easterly Waves-NASA's AMMA Field Study of Tropical Cyclogenesis, Bull. Am. Meteorol. Soc., 90, 1137-1156, doi:10.1175/2009BAMS2728.1, 2009. 